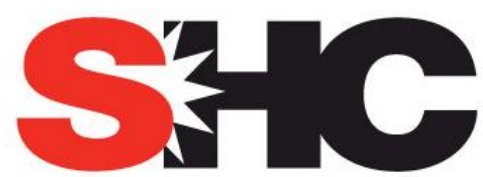

SOLAR HEATING \& COOLING PROGRAMME INTERNATIONAL ENERGY AGENCY
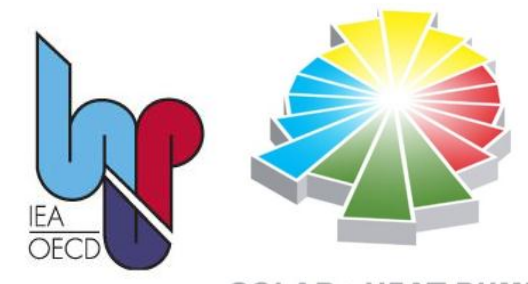

SOLAR + HEAT PUMP

\title{
Definition of Main System Boundaries and Performance Figures for Reporting on SHP Systems
}

\section{Deliverable B1}

Date: 15 December 2013

\section{Ivan Malenković,}

AIT Austrian Institute of Technology GmbH, Energy Department, Giefinggasse 2, 1210 Vienna, Austria

Phone : +43505506350

Fax : +43505506679

e-mail : ivan.malenkovic@ait.ac.at

\section{$\underline{\text { Contributors }}$}

\section{Peter Pärisch}

Institut für Solarenergieforschung Hameln GmbH (ISFH), Am Ohrberg 1, 31860 Emmerthal, Germany

\section{Sara Eicher, Jacques Bony}

Haute Ecole d'Ingénierie et de Gestion du Canton de Vaud, Laboratoire d'Energétique Solaire et de Physique du Bâtiment (LESBAT), Centre St-Roch, av. des Sports 20, 1400 Yverdon-les-Bains, Switzerland

\section{Michael Hartl}

AIT Austrian Institute of Technology $\mathrm{GmbH}$, Energy Department, Giefinggasse 2, 1210 Vienna, Austria

Type of document: final 


\section{Contents}

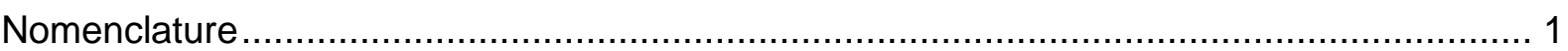

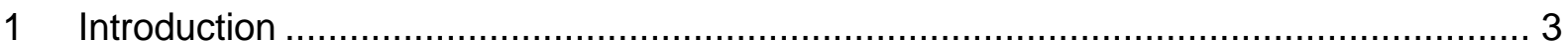

2 Overview of performance figures for SHP systems and components.......................... 5

2.1 Overview of performance figures in current normative documents .......................5

2.2 Deficiencies of current standards and guidelines for application to SHP

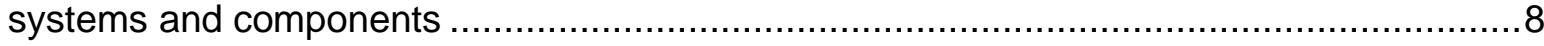

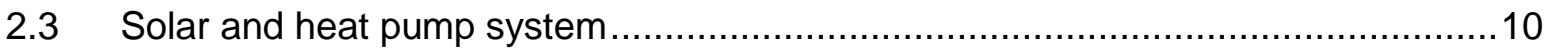

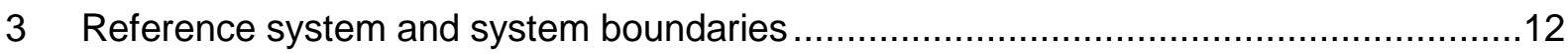

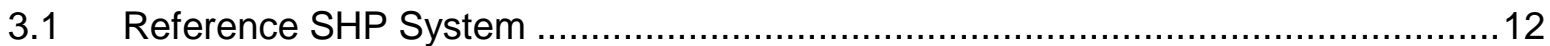

3.2 Definition of system boundaries …............................................................

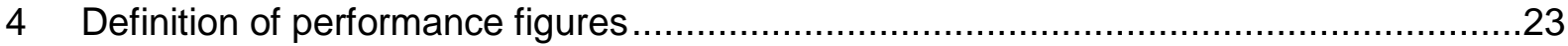

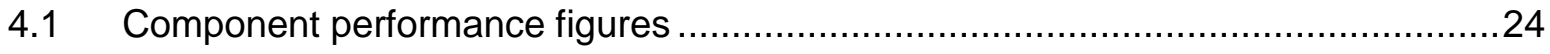

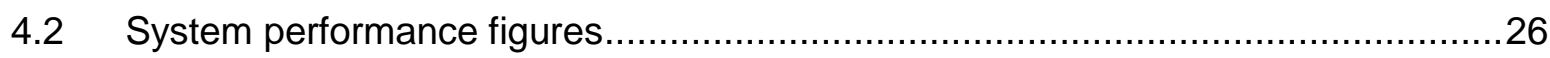

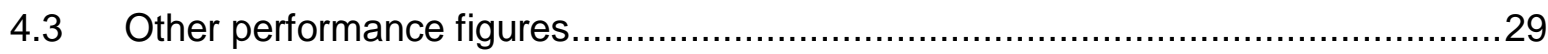

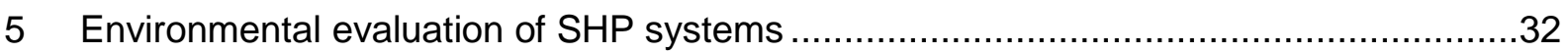

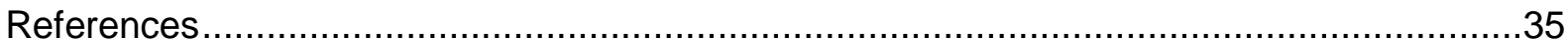

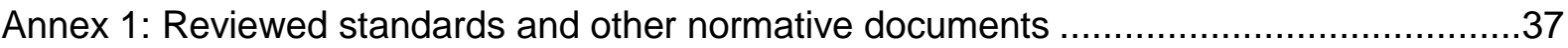




\section{Nomenclature}

$\begin{array}{llll}A & \text { Area in } \mathrm{m}^{2} & \dot{I} & \text { Solar irradiation in W } \\ C E D & \text { Cumulative Energy Demand } & P & \text { Power in W } \\ \text { COP } & \text { Coefficient of Performance } & P E R & \text { Primary Energy Ratio } \\ \dot{E} & \text { Energy flux in W } & \dot{Q} & \text { Thernal power in W } \\ E E R & \text { Energy Efficiency Ratio } & S C O P & \text { Seasonal COP } \\ G W P & \text { Global Warming Potential } & \text { SEER } & \text { Seasonal Energy Efficiency Ratio } \\ f_{\text {sav }} & \text { Fractional energy savings } & S P F & \text { Seasonal Performance Factor } \\ f_{\text {sol }} & \text { Solar fraction } & P E E F & \text { Primary Energy Effort Figure } \\ G & \text { Irradiance in W per } \mathrm{m}^{2} & & \\ & & & \\ \eta & \text { Efficiency } & \omega & \text { Collector utilisation ratio }\end{array}$

\section{Subscripts, capital}

$\begin{array}{ll}\text { BU } & \text { Back-up unit } \\ \text { C } & \text { Cooling, low temperature } \\ \text { COM } & \text { Cooling operation mode } \\ \text { CU } & \text { Control unit } \\ \text { DHW } & \text { Domestic hot water } \\ \text { FE } & \text { Final energy } \\ \text { H } & \text { High temperature } \\ \text { HOM } & \text { Heating operation mode } \\ \text { HP } & \text { Heat pump } \\ \text { HR } & \text { Heat rejection }\end{array}$

HS Heat source

HX Heat exchanger

NRE Non-renewable

PE Primary energy

SC Solar collector(s)

$\mathrm{SH} \quad$ Space heating

SHP Solar and heat pump

SHP+ Solar and heat pump plus energy

UE Useful energy

\section{Subscripts, small}

$\begin{array}{llll}\text { bSt } & \text { Before storage } & \text { on } & \text { Active operation mode } \\ \text { circ } & \text { circulation } & \text { prim } & \text { Primary } \\ \text { coll } & \text { Collector(s) } & \text { rad } & \text { Radiative } \\ \text { el } & \text { Electrical } & \text { ref } & \text { Reference } \\ \text { h } & \text { Heating } & \text { ren } & \text { Renewable } \\ \text { g } & \text { Global } & \text { sys } & \text { System } \\ \text { off } & \text { Idle operation mode } & & \end{array}$




\section{Abbreviations}

$\begin{array}{ll}\text { CCT } & \text { Concise Cycle Test } \\ \text { CTSS } & \begin{array}{l}\text { Component Test System } \\ \text { Simulation }\end{array} \\ \text { DHW } & \text { Domestic Hot Water } \\ & \text { European Heat Pump } \\ \text { EHPA } & \text { Association } \\ \text { EN } & \text { European Norm } \\ \text { GWP } & \text { Global Warming Potential }\end{array}$

HPP Heat Pump Programme

IEA International Energy Agency

ISO International Standardisation

Organisation

SHC Solar Heating and Cooling (Programme)

SHP Solar and Heat Pump

VDI Verein Deutscher Ingenieure 


\section{Introduction}

\section{From the Legal Text of SHC Task 44}

"The objective of this subtask is to reach a common definition on what are the figures of merits of solar and heat pump systems and how to assess them.

This work can lead to pre-normative definition on how to test and report the performance of a combined solar and heat pump system.

The output of this subtask should ideally be used by the industry to communicate the performances of the system they promote, like in the solar collector market collectors are reported with their efficiency curve which makes them comparable with others at least on one important criterion which is the energy performance."

\section{Deliverable B1: Definition of performance indicators}

"A review of the state-of-the-art of how several authors and experts define a system performance indicator will be done. The work is about combining the solar fraction or solar savings fraction with a COP (coefficient of performance used in the heat pump world or annual SPF (seasonal performance factor) definition, that captures all the aspects of the combination and reports the physics and economics of a combined system.

The performance can be stated at nominal conditions (COP of the heat pump for instance) or integrated over one year (SPF). Both values are of importance.

Proposals of various definitions will be made, tested on known systems and discussed with heat pump experts. If a calculation method for e.g. SPF involves numerical simulation, a close collaboration with Subtask $\mathrm{C}$ will ensure the usage of verified, state-of-the-art models and simulation techniques.

A common definition will be decided upon and the other subtasks will use it thus providing a good test platform."

Therefore, there is a need to decide on the definitions of performance figures for:

1. The components, for the component tests which may also be used for system evaluations e.g. by the Component Test System Simulation (CTSS) method;

2. The whole system and its subsystems, for the system analysis and optimisation, as well as for comparison of SHP systems among each other (including quality assurance - performance reporting), using e.g. monitoring results or whole system test (WST) results;

3. The whole system, for comparison of SHP systems to other systems in terms of e.g. energy efficiency, primary energy efficiency, emissions etc.

The work in Subtask B regarding the definition of performance figures (Deliverable B1), its relation to other topics of Subtask $B$ and to other subtasks is tentatively shown in Figure 1-1. 


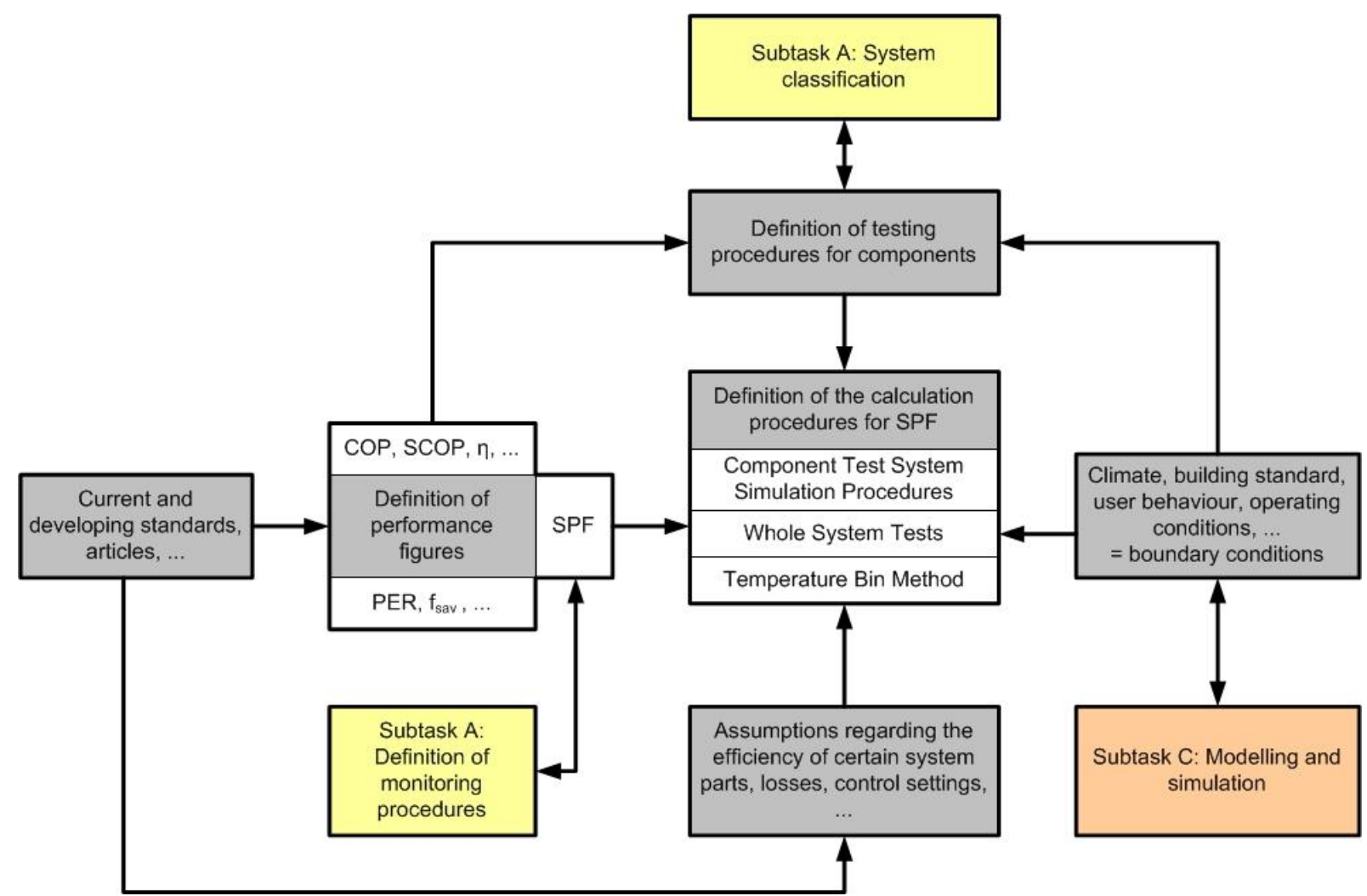

Figure 1-1 - Overview of the test and performance evaluation related work in Subtask B 


\section{Overview of performance figures for SHP systems and components}

\subsection{Overview of performance figures in current normative documents}

A variety of national and international standards and other normative documents are available both for heat pump and solar thermal technologies. These documents cover component and system testing, as well as calculation methods for their performance prediction. In most of them performance figures are defined, both for components and for systems containing more than one component (e.g. heat pump and storage). Analysing these documents, however, it soon becomes obvious, that there are different definitions of the same performance figure, or that the same energy balance defining a performance figure is indicated in a different manner.

Within Task 44 / Annex 38, a number of significant normative documents for both heat pumps and solar thermal were collected and analysed. From this analysis, a coherent nomenclature system for different performance figures was defined, which was applied on the systems investigated within the activity. This nomenclature is used throughout the Task / Annex, if not stated differently. For example, in some cases, system performance was evaluated before the definition of the nomenclature. In these cases, system boundaries might differ from the ones described here.

As at the time of writing the report no normative documents for testing of combined solar thermal and heat pump systems were available, mainly documents covering single technologies were analysed. However, within the European Commission's Directives on ecodesign and eco-labelling of energy using products, calculation methods for the energy efficiency of space heating devices, including combinations thereof, have been published. A current status is given in chapter 2.3.

\subsubsection{Heat pump}

National and international standards and guidelines for heat pump testing and performance assessment are well developed and widely used in all important markets worldwide. In many regions, they are commonly used as a basis for marketing tools such as quality labels, subsidies etc. They are available for heating, domestic hot water (DHW) and cooling applications. Generally, the performance for each application is being calculated separately. Some documents however contain figures which take into account both heating and domestic hot water production. The performance for simultaneous heating and cooling or cooling and DHW are not covered in any of the collected documents.

In the reviewed standards and guidelines, the following nomenclature and definitions of performance figures are used (Table 2-1). The list of collected and reviewed standards and guidelines is provided in Annex 1, documents 1 to 12 . 
IEA SHC Task 44 / HPP Annex 38 - http://www.iea-shc.org/task44

Table 2-1 - Overview of the performance figures for heat pumps and heat pump systems defined in different standards and guidelines

\begin{tabular}{|c|c|c|}
\hline \multicolumn{3}{|c|}{ Heat Pump Standards } \\
\hline Standard/Guideline & PF & Definition \\
\hline \multirow[t]{2}{*}{ EN 14511} & COP & $\begin{array}{l}\text { The COP is defined as the ratio of the heat output of the heat pump unit } \\
\text { to the effective energy input to the unit for a steady state operating } \\
\text { condition. Energy inputs and outputs are corrected for the pumping } \\
\text { energy needed to overcome the pressure drop losses on the heat } \\
\text { exchangers inside the unit. }\end{array}$ \\
\hline & EER & $\begin{array}{l}\text { Same definition as for the COP, used for cooling applications (useful } \\
\text { energy is cooling). }\end{array}$ \\
\hline EN 15879-1 & COP / EER & $\begin{array}{l}\text { Uses same definitions as EN 14511, applied on direct expansion heat } \\
\text { pumps. }\end{array}$ \\
\hline EN 16147 & COP & $\begin{array}{l}\text { Defined as the ratio of the useful heat delivered for the production of } \\
\text { domestic hot water and consumed electricity over a tapping cycle. The } \\
\text { system includes the heat pump, the storage tank and the circulation } \\
\text { pump. Tank losses are accounted for. }\end{array}$ \\
\hline \multirow{2}{*}{ AHRI 320/325/330 } & COP & $\begin{array}{l}\text { A ratio of the heating capacity, excluding supplementary resistance } \\
\text { heat, to the power input for steady state operating conditions. }\end{array}$ \\
\hline & EER & $\begin{array}{l}\text { Same definition like the COP, used for cooling applications (useful } \\
\text { energy is cooling). }\end{array}$ \\
\hline \multirow{2}{*}{$\begin{array}{l}\text { ISO } 13256-1 / \\
\text { ISO } 13256-2\end{array}$} & $\mathrm{COP}$ & $\begin{array}{l}\text { Ratio of the net heating capacity to the effective power input of the } \\
\text { equipment at steady state operating conditions. The power inputs and } \\
\text { outputs are corrected in the same way as in EN } 14511 \text {. }\end{array}$ \\
\hline & EER & $\begin{array}{l}\text { Same definition like the COP, used for cooling applications (useful } \\
\text { energy is cooling). }\end{array}$ \\
\hline \multirow[t]{2}{*}{ EN 14825} & SCOP & $\begin{array}{l}\text { Ratio of the overal heating energy delivered over a one year time period } \\
\text { to the total energy input to the system. It is a calculatory value obtained } \\
\text { under certain assumptions regarding the heating load, climate, controls } \\
\text { etc. The basis for the calculation are unit tests, e.g. according to EN } \\
\text { 14511. }\end{array}$ \\
\hline & SEER & Same as SCOP, but for cooling applications. \\
\hline \multirow[t]{2}{*}{ ASHRAE 116} & HSPF & $\begin{array}{l}\text { Ratio of the total heat delivered over the heating season (not exceeding } \\
12 \text { months) to the total energy input over the heating season. It is a } \\
\text { calculatory value obtained under certain assumptions regarding the } \\
\text { heating load, climate, controls etc. The basis for the calculation are unit } \\
\text { tests. }\end{array}$ \\
\hline & SEER & $\begin{array}{l}\text { Ratio of the total heat removed during the normal period of usage for } \\
\text { cooling (not exceeding } 12 \text { months) to the total energy input during the } \\
\text { same period. Obtained similarly to the HSPF. }\end{array}$ \\
\hline VDI 4650-1 & $\operatorname{SPF}(e)$ & $\begin{array}{l}\text { The ratio of the useful heat delivered in the period of one year over the } \\
\text { electrical energy used to drive the compressor and some auxiliary } \\
\text { drives. It is a calculatory figure based on the test results from EN } 14511 . \\
\text { It does not take into account electricity consumption for e.g. ground } \\
\text { water pump, heat pump off-mode etc. }\end{array}$ \\
\hline EN 15316-4-2 & SPF & $\begin{array}{l}\text { SPF is defined as the ratio of the overal energy output to the overal } \\
\text { energy input (final energy) of the heat pump system for heating and } \\
\text { DHW. The heat pump system includes the heat pump unit, heat source, } \\
\text { water storages and all auxiliary systems (controls, liquid pumps etc.). }\end{array}$ \\
\hline
\end{tabular}


From Table 2-1, some conclusions regarding the nomenclature and definition of specified performance figures can be made:

COP - Coefficient of Performance: In all reviewed standards it is used for the performance of the heat pump unit under stationary operating conditions. An exception is the EN 16147, where the system heat pump with DHW storage is considered and the figure is calculated for a set of different, partly transient operating conditions. The influence of the liquid circulation pumps on the energy inputs and outputs differ among the standards. It is generally used for heating applications only.

EER - Energy Efficiency Ratio: Same like COP, but used for cooling applications in most of the European Standards. In many US standards defined as Btu/hr of cooling energy per W electricity consumption.

SCOP - Seasonal Coefficient of Performance: Used only in one standard to express the calculated seasonal heating efficiency of the heat pump for an assumed climate, buildingload etc.

SEER - Seasonal Energy Efficiency Ratio: Same like SCOP, but for cooling applications.

SPF - Seasonal Performance Factor: In European standards (e.g. EN 15316-4-2), the SPF used as a figure to express the efficiency of the overall system including all auxiliary components like circulation pumps, storages, back-up heaters etc. In the VDI guideline used to express roughly the same efficiency as the SCOP - not taking into account the whole system but only the heat pump unit with some auxiliary energy. Its equivalent in the US standards is the Heating SPF-HSPF.

\subsubsection{Solar thermal}

Unlike for the heat pumps, there are standards available for testing and performance evaluation both for collectors and for whole systems (references to the documents are listed in Annex 1, documents 13 through 20. Table 2-2 gives an overview.

There is a high level of agreement between the reviewed standards for solar thermal applications regarding the definition of performance figures and the used nomenclature. Four main performance indicators are found:

For $\eta$ - Collector Thermal Efficiency, $f_{\text {sol }}$ - Solar Fraction and $f_{\text {sav }}$ - Fractional Energy Savings, the same definition was found in all analysed standards.

Thermal Performance: In the reviewed standards, no system performance figure similar to SPF for the heat pump systems was found. However, from the delivered heat and the parasitic energy, as defined in the reviewed standards (Table 2-2), the efficiency of the system could be calculated in the same manner as for the heat pump systems. 
Table 2-2 - Overview of the performance factors for solar thermal collectors and solar thermal systems defined in different standards

\begin{tabular}{|c|c|c|}
\hline \multicolumn{3}{|c|}{ Solar Thermal Standards } \\
\hline Standard & PF & Definition \\
\hline EN 12975-2 & $\eta$ & $\begin{array}{l}\text { The Collector Thermal Efficiency is the ratio of the energy removed by } \\
\text { the heat transfer fluid over a specified time period, to the product of a } \\
\text { defined collector area (gross, absorber or aperture) and the solar } \\
\text { irradiation incident on the collector for the same period, under steady } \\
\text { or non-steady state conditions (according to ISO 9488). }\end{array}$ \\
\hline \multirow{2}{*}{$\begin{array}{l}\text { ISO 9806, } \\
\text { ASHRAE } 93\end{array}$} & $\eta$ & Same as EN 12975. \\
\hline & $\eta g$ & $\begin{array}{l}\text { Collector Thermal Efficiency, defined as the actual collected useful } \\
\text { energy to the solar energy intercepted by the collector gross area. }\end{array}$ \\
\hline \multirow{3}{*}{ EN 12976, EN12977 } & fsol & $\begin{array}{l}\text { Solar Fraction is the energy supplied by the solar part of a system } \\
\text { divided by the total system load. The solar part of a system and any } \\
\text { associated losses need to be specified, otherwise the solar fraction is } \\
\text { not uniquely defined (according to ISO 9488). }\end{array}$ \\
\hline & fsav & $\begin{array}{l}\text { Fractional Energy Savings is the reduction of purchased energy } \\
\text { achieved by the use of a solar heating system, calculated as } 1 \text { - } \\
\text { [(auxiliary energy used by solar heating system)/(energy used by } \\
\text { conventional heating system)] in which both systems are assumed to } \\
\text { use the same kind of conventional energy to supply the user with the } \\
\text { same heat quantity giving the same thermal comfort over a specified } \\
\text { time period (according to ISO 9488). }\end{array}$ \\
\hline & $\begin{array}{c}\text { Thermal } \\
\text { performance }\end{array}$ & $\begin{array}{l}\text { The thermal performance is defined as a set of performance indicators. } \\
\text { For solar systems without auxiliary energy sources, these are: The heat } \\
\text { delivered by the solar heating system, QL; the solar fraction, fsol; the } \\
\text { parasitic energy, Qpar. For systems including auxiliary energy sources: } \\
\text { The net auxiliary energy demand, Qaux, net; the fractional energy } \\
\text { savings, fsav; the parasitic energy, Qpar. }\end{array}$ \\
\hline ISO 9459 & $\begin{array}{c}\text { Thermal } \\
\text { performance }\end{array}$ & Comparable definition to EN 12976 and EN 12977. \\
\hline EN 15316-4-3 & & Same nomenclature as in EN 12977. \\
\hline
\end{tabular}

\subsection{Deficiencies of current standards and guidelines for application to SHP systems and components}

In Deliverable B3, a number of methods for testing and performance evaluation of SHP systems currently being developed by different research institutes in Europe are briefly described. There are currently two basic approaches:

- system oriented approach - the whole system or part of the system is tested with defined boundary conditions and the results are used either for parameter identification of the models and simulation of the performance, or for the estimation of system performance by extrapolation (e.g. Concise Cycle Test - CCT, Short Cycle System Performance Test - SCSPT etc. See Papillon et al. (2011);

- component oriented approach - component testing system simulation (CTSS) method.

As stated previously, there are currently no standards or guidelines for testing and performance evaluation of SHP systems. In future, however, some of the documents described in previous subchapters could be extended in order to use them for SHP system performance evaluation. Comparing the method descriptions and existing normative 
documents with the available SHP products on the market and considering the multitude of existing system configurations, the following can be concluded:

Heat pump standards and guidelines:

- The operating conditions for heat pump testing provided in EN 14511 and EN 15879-1 should be extended to cover higher temperature ranges on the heat source side which may occur in some serial SHP systems due to interactions with the solar part of the system;

- Additional heat sources with typical temperature levels should be added to the standards, e.g. hybrid collectors or direct evaporation of refrigerant in solar collectors;

- Heat pumps with a desuperheating heat exchanger for DHW preparation are not covered by current standards;

- There are almost no procedures for transient testing of heat pumps (defrosting is included in EN 14511, partly transient conditions within EN 16147 for DHW), a feature especially important for the component characterisation and parameter identification within certain methods;

- Test sequences and requirements for capacity controlled heat pumps are still not fully developed;

- The performance calculation methods described in EN 14825 and EN 15316-4-2 (temperature bin methods) are difficult to extend to SHP systems, mainly because of the solar irradiation, storage effects (both on the heat source as well as on the heat sink side) and different control concepts. However, some related work has been done on that issue, e.g. Anderson et al. (1980) or Nuñez et al. (2011) and further developments are expected.

Standards for solar thermal collectors:

- Some of the collector types common in SHP systems are not included in the standards and/or quality assurance schemes, such as hybrid or PVT collectors. More information on the status of quality assurance for PVT collectors is available in Kramer and Helmers (2013).

- Collectors with direct evaporation of the refrigerant are not yet covered by the reviewed standards;

- In SHP systems, collectors can operate under lower operating temperatures providing heat for heat source regeneration or directly to the heat pump evaporator. In cases of unglazed or hybrid collectors, a large portion of that heat may originate from the ambient air, including condensation on the collector surface. These effects are currently not covered by the standards. However, in Perers et al. (2011), a proposal for an extension of EN 12975 in this respect was presented.

Standards for solar thermal systems:

- The heat pump could be seen as an auxiliary heat source for the solar combisystem in parallel SHP systems. However, more complex SHP configurations need further investigations. For example, stratification efficiency and hydraulic integration of thermal storages have a substantial influence on the operating conditions of the heat pump and thus to the SPF of the overall system, Haller et al. (2013). Current one-dimensional storage models do not consider the influence of the charging and discharging mass flows on the stratification efficiency and are of limited use for annual simulations of SHP systems; 
- The performance prediction methods apply currently only to a limited number of welldefined system configurations, mostly for pre-fabricated systems. However, as documented in the Deliverables of Subtask A, there is a large variety of configurations within SHP systems. Further work towards grouping certain configurations would be helpful to simplify the testing and calculation procedures and limit the number of parameters and boundary conditions needed;

- The models provided in standards for the CTSS method do not apply to certain special components. Moreover, appropriate heat pump models have to be added and test sequences developed or current documents extended);

- The reference operating conditions for the "black box" methods are suitable only for specified system configurations. New operating conditions would have to be developed and validated;

- The methods do not account for multiple sources and sinks for each of the subsystems, nor for complex control algorithms often found in SHP systems.

\subsection{Solar and heat pump system}

At the time this report was written, the EU already established the "European Union EcoDesign Directive for Energy Related Products" (EU (2009)). In it, different types of energy related products are arranged in lots according to their purpose. Devices for space and combined space heating and domestic hot water preparation with heating capacity lower than $400 \mathrm{~kW}$ are covered by lot 1 and pure domestic hot water heaters and hot water storage tanks are covered by lot 2 .

The Directive is providing rules for labelling of products for heating and domestic hot water preparation similarly to the label already known from various electric home appliances. The classification is made according to the calculated energy efficiency $\left(\eta_{\mathrm{s}}\right)$. The products with classes between $\mathrm{A}+++$ and $\mathrm{G}$ - with $\mathrm{A}+++$ for the most efficient and $\mathrm{G}$ for the least efficient products - make energy consumption of the heating installations transparent and motivate the consumer to focus on energy efficient products. Table 2-3 gives an overview of the most important documents related to that directive.

Table 2-3: Overview of the relevant regulations and standards with regard to energy labelling and ecodesign

Commission Delegated Regulation (EU) No 811/2013 of 18 February 2013 supplementing Directive 2010/30/EU of the European Parliament and of the Council with regard to the energy labelling of space heaters, combination heaters, packages of space heater, temperature control and solar device and packages of combination heater, temperature control and solar device

Commission Delegated Regulation (EU) No 812/2013 of 18 February 2013 supplementing Directive 2010/30/EU of the European Parliament and of the Council with regard to the energy labelling of water heaters, hot water storage tanks and packages of water heater and solar device

Commission Regulation (EU) No 813/2013 of 2 August 2013 implementing Directive 2009/125/EC of the European Parliament and of the Council with regard to ecodesign requirements for space heaters and combination heaters

Commission Regulation (EU) No 814/2013 of 2 August 2013 implementing Directive 2009/125/EC of the European Parliament and of the Council with regard to ecodesign requirements for water heaters and hot water storage tanks

EN 14825-2012; Air conditioners, liquid chilling packages and heat pumps, with electrically driven compressors, for space heating and cooling - Testing and rating at part load conditions and calculation of seasonal performance 
The energy efficiency $\left(\eta_{\mathrm{s}}\right)$ is calculated according to the Eco Design regulation and the related standards. $\eta_{\mathrm{s}}$ is closely related to the PER from chapter 5.1.1. Equation 1 gives the energy efficiency for heat pumps with SCOP determined from EN 14825 according to the European Commission Regulation No. 813/2013.

$$
\eta_{\mathrm{s}}=\frac{S C O P}{C C}-F_{\mathrm{i}}=P E R
$$

In equation 1, the conversion coefficient $(C C)$ is 2.5 for electricity used for vapour compression heat pumps. The correction factors $F_{\mathrm{i}}$ are expressed in $\%$ and are accounting for negative contribution to the seasonal space heating energy efficiency of heaters mainly due to the system controls. Their calculation method is still in a draft version.

The need for the labelling of combined systems, as investigated in this report, has been recognized by the commission. Therefore the label for the "packages of combination heater, temperature control and solar devices" was introduced to the Regulation (EU) No 811/2013. This label allows for accounting additional heat input from supplementary space heating devices such as solar devices. However, the method is very simple and there is a need to investigate if it can be used for fair and consistent evaluation of SHP systems considering the variety and complexity of existing products and applications. 


\section{Reference system and system boundaries}

\subsection{Reference SHP System}

The basis for the energy performance evaluation of an energy transformation system, in the common sense of the term, is energy balancing, i.e. summing up its energy inputs and outputs and establishing a relationship between them. As a great variety of different SHP system configurations is available on the market (see Deliverables of Subtask A), a comparison of the system performances among them might present a challenge. This is even more so, if the systems are not considered just as "black-boxes" but a deeper analysis is aimed at.

For every transparent and reliable performance comparison among different systems, it is necessary to define comparable system boundaries for energy balancing - i.e. an exact definition of relevant energy inputs and outputs to and from the system, which should be as much independent regarding the system configuration as possible. For that purpose Task 44 / Annex 38 proposed a "reference system" which ideally contains all component arrangements and energy flows of the known configurations. System boundaries for performance evaluation and analysis were defined for that system. The boundaries for particular configurations can then be obtained by removing non-existing components and energy flows from the reference system.

Please note, that the term "energy" refers to the energy content flowing across the system boundary. If e.g. the back-up heating is a fuel-driven boiler, then the measurement point (and the energy flow at that point) for the fuel input has to be defined.

The representation of the proposal is shown in Figure 3-1, the nomenclature and abbreviations used are provided in the Nomenclature section at the beginning of the report. The representation method used is based on the work by Frank et al. (2010). However, as the system in Figure 3-1 represents a generic configuration, some simplifications have been made in order not to overload the representation:

- Ambient and Exhaust Air, Ground Water, Ground and Waste Heat can all be considered as heat sources for the heat pump $\left(\dot{Q}_{H S}\right)$ or heat sinks in the case of free cooling $\left(\dot{Q}_{F C}\right)$ or energy dissipation for active cooling $\left(\dot{Q}_{H R}\right)$. They, as well as the respective heat exchangers, were put together as "free energy sources" and indicated with an orange frame (slashed for heat exchangers);

- Solar collectors can generally transform both solar radiation and heat from ambient air (including latent heat) into useful heat or heat source for the heat pump (either directly or for the regeneration of the ground, air pre-heating etc.). This fact has been considered by putting Air and Sun together within the yellow frame. The energy input to the collector is denominated as $G \cdot A_{\text {coll }}$ (which equals the total irradiation on the collectors) for the solar radiative part and $\dot{Q}_{\text {coll,air }}$ for the energy input from the ambient air;

- Traded energy includes electricity and other energy carriers, denominated with "Energy carrier X"; 


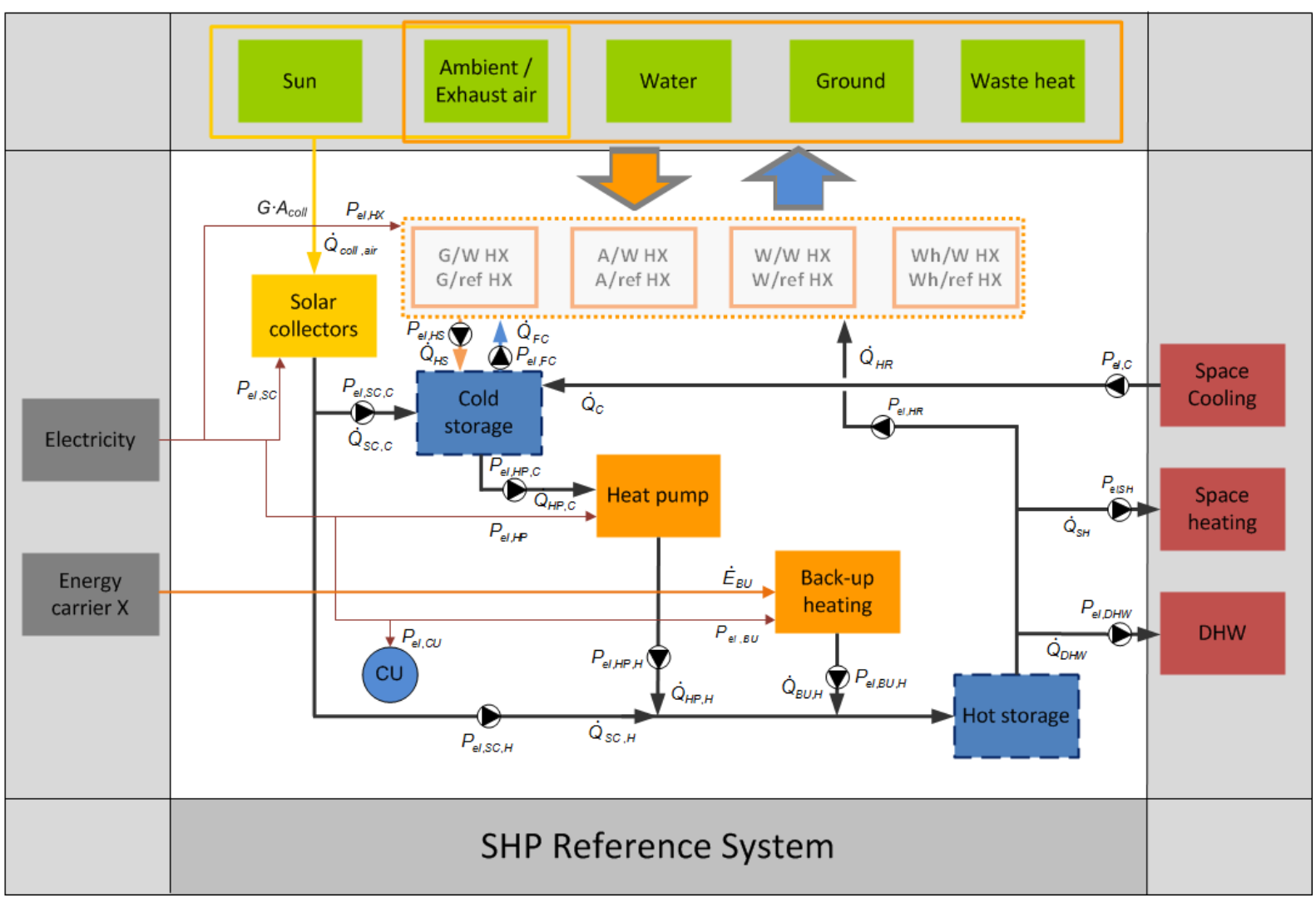

Figure 3-1 - Reference SHP system

- Component denominated as "CU" represents the electricity consumption of all control unit(s) of the system not included in the consumption of component-specific controls, e.g. heat pump or solar system control. In many cases, however, it is very difficult or even impossible to clearly define the electricity consumption of the control unit(s) for some subsystems within their respective system boundaries. As always, common sense should be used and the chosen approach described;

- Obviously, the pumps and some other components not represented in Figure 3-1 (e.g. valves) also consume electricity. In order not to overload the representation, electricity consumption of the pumps are considered with the pump symbol and other components are not included. In real systems, however, their energy consumption should be considered appropriately;

- In many systems, hydraulic connections allow energy transport to and from the heat pump bypassing the heat storage(s) or the system does not contain one or both of the represented heat storages. To avoid overloading the diagram with the representation of these energy flows, both storages have been represented within a dashed frame. This means, that in case a storage is bypassed or not existent in a system, it should not be taken into account or it represents just a hydraulic connection. For example, if the solar collector and a borehole are both directly connected to the evaporator of the heat pump, then the cold storage is reduced to a nodal point for $\dot{Q}_{H S}, \dot{Q}_{S C, C}$ and $\dot{Q}_{H P, C}$.

Note that the energy flows are represented in their physical flow direction, from higher to lower temperatures. The connections between the components do not necessarily reproduce the hydraulic configuration of the system. They however provide information on possible interactions between the components, due to the hydraulics and the control strategy of the system. The connections between components with a pump symbol represent energy 
consumption needed to transport the heat transfer medium and overcome the pressure losses within the system. These consumptions generally represent a substantial part of the system energy input and have to be considered appropriately. In some systems one pump can be used to transport the heat transfer medium from one to several components. For example, one pump can be used to circulate the fluid from the collector both to the evaporator of the heat pump and to the heat storage. This implies, that this pump would be consuming both $P_{e l, S C, H}$ and $P_{e l, S C, C}$. This has to be considered when balancing the system using measurement data or simulation results. In analogy, one connection from Figure 3-1 can in reality contain more than one circulation pump due to heat exchangers. For example, although presented as one component, "hot storage" can actually consist of more than one unit (e.g. one storage for heating and one for DHW). This implies, that e.g. the energy input $P_{e l, S C, H}$ can in reality consist of more than one consumer (pump). This has to be taken into account when calculating the overall energy input to the system.

\subsection{Definition of system boundaries}

As previously mentioned, the aim of the definition of system boundaries was to establish generally applicable principles, largely regardless of the technology and system configuration. The principles were therefore discussed and proposed together with another international activity, IEA HPP Annex 34 - Thermally Driven Heat Pumps for Heating and Cooling (www.annex34.org), which focused on thermally driven heat pumps for heating and cooling. Similar approach developed within the project SEPEMO-Build (Seasonal Performance Factor and Monitoring for Heat Pump Systems in the Building Sector, www.sepemo.eu) for electrically driven compression heat pump systems in buildings was also considered. When defining the boundaries, two main goals were pursued:

- The boundaries should allow a simple application to different SHP-systems, but also to other technologies for transparent comparison of different products regarding different performance aspects (energy, economics, environment etc.);

- The boundaries should cover the needs of different target groups and allow for a simple analysis of a system operation by comparing the performance within different system boundaries.

Starting from these two goals, the following five main principles for the definition of system boundaries were proposed in Table 3-1. When applied to the reference system from Figure 3-1, specific system boundaries for SHP systems can be defined as:

1. SHP system with the useful energy distribution systems (SHP+)

2. SHP system without the useful energy distribution systems (SHP)

3. SHP system without the useful energy storage (bSt)

4. Heat pump with the heat source / heat rejection subsystems $(\mathrm{HP}+\mathrm{HS})$

5. Heat pump, solar collector, back-up unit (HP, SC, BU) 
Table 3-1 - Overview of main principles for the definition of system boundaries for performance evaluation of SHP Systems

\begin{tabular}{|c|c|c|}
\hline System Boundary & Purpose & Target Group \\
\hline $\begin{array}{l}\text { Overall system performance including energy } \\
\text { distribution system }\end{array}$ & $\begin{array}{l}\text { Possibility of an energy, economy and ecology related evaluation } \\
\text { of the whole system - overall energy balance, traded energy, } \\
\text { free energy, emissions etc. }\end{array}$ & Users, policy makers, statistical evaluation \\
\hline $\begin{array}{l}\text { Overall system performance without the } \\
\text { energy distribution system }\end{array}$ & $\begin{array}{l}\text { Possibility of an energy, economy and ecology related evaluation } \\
\text { of the energy producing system, without the energy distribution } \\
\text { system, which may vary for different applications. Comparison } \\
\text { between different systems and technologies, product quality } \\
\text { assurance, labelling }\end{array}$ & $\begin{array}{l}\text { Manufacturers, planers, installers, users, funding } \\
\text { institutions, policy makers }\end{array}$ \\
\hline $\begin{array}{l}\text { Performance of the system without the } \\
\text { influence of the end-user storage losses }\end{array}$ & Mainly interesting for system analysis - storage management & System and component manufacturers, planners \\
\hline $\begin{array}{l}\text { Performance of each energy transformation } \\
\text { unit, including all parts needed for its proper } \\
\text { functioning }\end{array}$ & $\begin{array}{l}\text { Performance of each unit under given circumstances gives } \\
\text { information about the efficiency of every subsystem and possible } \\
\text { improvements }\end{array}$ & $\begin{array}{l}\text { Component and subcomponent manufacturers, } \\
\text { planners and installers }\end{array}$ \\
\hline $\begin{array}{l}\text { Performance of each energy transformation } \\
\text { unit itself, without influence of the auxiliary } \\
\text { energy }\end{array}$ & $\begin{array}{l}\text { This closely corresponds to the energy balance used currently in } \\
\text { most quality assurance schemes both for solar thermal collectors } \\
\text { and heat pumps (e.g. Solar Keymark, EHPA Quality Label). By } \\
\text { comparison with other performance figures, an analysis of the } \\
\text { system regarding peripheral energy consumption can be made }\end{array}$ & $\begin{array}{l}\text { System and component manufacturers, planners, } \\
\text { installers }\end{array}$ \\
\hline
\end{tabular}


The reference system and five boundaries for heating and cooling applications are shown in Figure 3-3 through Figure 3-6. Note that boundaries bSt and HP+HS differ for heating and cooling operation modes. In the first case, this is due to the definition of the useful energy storage. In the heating operation mode, the useful energy is stored in the hot storage, while the cold storage (if any) can be part of the energy source system for the heat pump. In the cooling operation mode, the energy extracted from the user, i.e. the useful cooling energy is stored in the cold storage and this component is excluded from the energy balance. For the $\mathrm{HP}+\mathrm{HS}$ subsystem, the heat source for the heating and heat sink system for the cooling operation mode differ and respective components have to be considered accordingly.

Boundaries SHP+ and SHP (Figure 3-3) are recommended for the comparison of SHP systems among each other, as well as for the assessment of the environmental impact of the systems in operation. Depending on the available data or purpose of the comparison, the one or the other boundary might be more appropriate.

The useful energy for space heating and cooling within these system boundaries is considered at the interface to the energy distribution system, e.g. at the heating circuit manifold. However, for the SHP+ boundary the energy input of the distribution system for circulation pumps, ventilators, controls etc. is considered and for the SHP boundary it is excluded from the energy balance.

The useful energy for DHW considered depends on the system configuration:

a) Systems without additional heating of the distribution pipes or secondary flow circulation:

- For fresh water systems (systems with a DHW heat exchanger - Figure 3-2 right, however without the circulation pump), the energy provided to the DHW distribution system at the secondary DHW lines, without the distribution losses after the connection (seen from the system point of view - after the heat exchanger);

- For direct systems (Figure 3-2 left, however without the circulation pump), the energy provided to the DHW distribution system at the connection of the supply line at the storage or at the heat pump or any other heat generating unit delivering DHW as useful energy, i.e. without the distribution losses after the connection.

b) Systems with additional heating of the distribution pipes:

In this case, the useful energy considered is the energy provided after the last energy input to the supply line, i.e. before or at the tap. If a measurement before the tap is not convenient or not possible, an approximation can be made by adding the electricity consumption for the heating of the distribution pipes both to the overall consumed electricity (full amount) and useful energy output (fully, if heating is needed and it can be assumed that most of the heat is not dissipated to the environment. Otherwise a certain fraction has to be assumed depending on the controls, tapping cycle, building type etc.).

c) Systems with flow circulation:

The useful energy is the same for both system configurations (direct and fresh water) and for both system boundaries - $Q_{D H W}$. However, the considered energy consumption attributed to the DHW distribution system varies for different system configurations, as shown in Figure 3-2 and Table 3-2.

- For fresh water systems, the energy consumption of the primary pump for domestic hot water preparation $P_{e l, D H W, \text { prim }}$ is included both in SHP and SHP+ boundaries, since it is considered to be an integral part of the SHP system. However, for system boundary SHP, only the energy consumption when 
delivering DHW is taken into account. Energy consumption of the circulation pump $P_{e l, D H W, c i r c}$ is considered only for the SHP+ system boundary.

- For direct systems, the energy consumption of the circulation pump $P_{e l, D H W, \text { circ }}$ is considered only for the SHP+ system boundary.

In both system boundaries the heat losses after the circulation loop should not be regarded as useful energy $Q_{D H W}$.

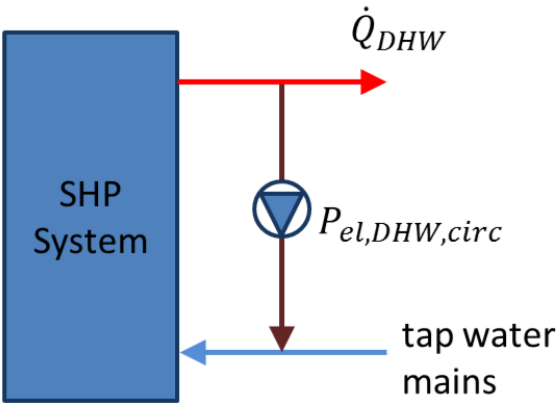

Direct DHW distribution system

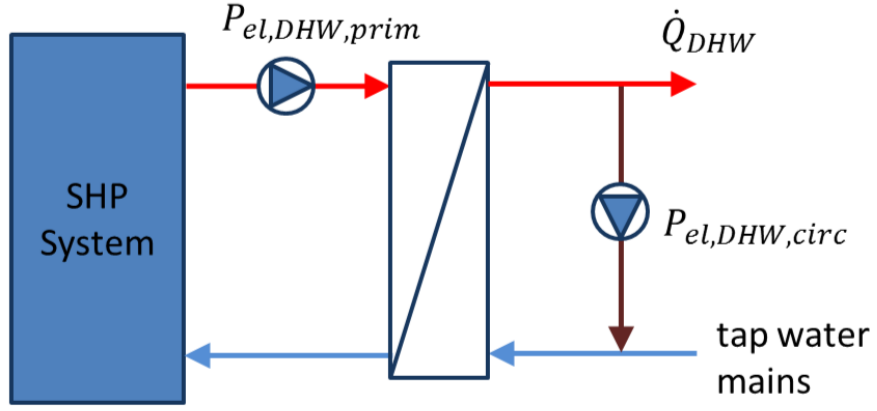

Fresh DHW distribution system

Figure 3-2 - Consideration of DHW secondary flow circulation for the energy consumption of the system regarding SHP and SHP+ system boundaries for direct systems (left) and fresh water systems (right)

Table 3-2 - Consideration of DHW circulation system energy consumption for SHP and SHP+ system boundaries

\begin{tabular}{|l|c|c|c|c|}
\cline { 2 - 5 } \multicolumn{1}{c|}{} & \multicolumn{2}{c|}{ direct system } & \multicolumn{2}{c|}{ fresh water system } \\
\cline { 2 - 5 } & SHP & SHP+ & SHP & SHP+ \\
\hline Useful energy & $\dot{Q}_{D H W}$ & $\dot{Q}_{D H W}$ & $\dot{Q}_{D H W}$ & $\dot{Q}_{D H W}$ \\
\hline Energy consumption & - & $P_{\text {el,DHW,circ }}$ & $P_{\text {el,DHW,prim }}$ & $\begin{array}{c}P_{\text {el,DHW,prim }} \\
+ \\
P_{\text {el,DHW,circ }}\end{array}$ \\
\hline
\end{tabular}

Reverse heat flows from the user, not intended for space cooling, e.g. for defrosting of airsource heat pumps, have to be taken into account and subtracted from the useful energy provided.

In the following chapter, the correlations for the calculation of the seasonal performance factors for these system boundaries will be shown for the reference system. Note, that the above considerations are to be taken into account, when calculating the electricity consumption for the DHW distribution, $P_{e l, D H W}$. 

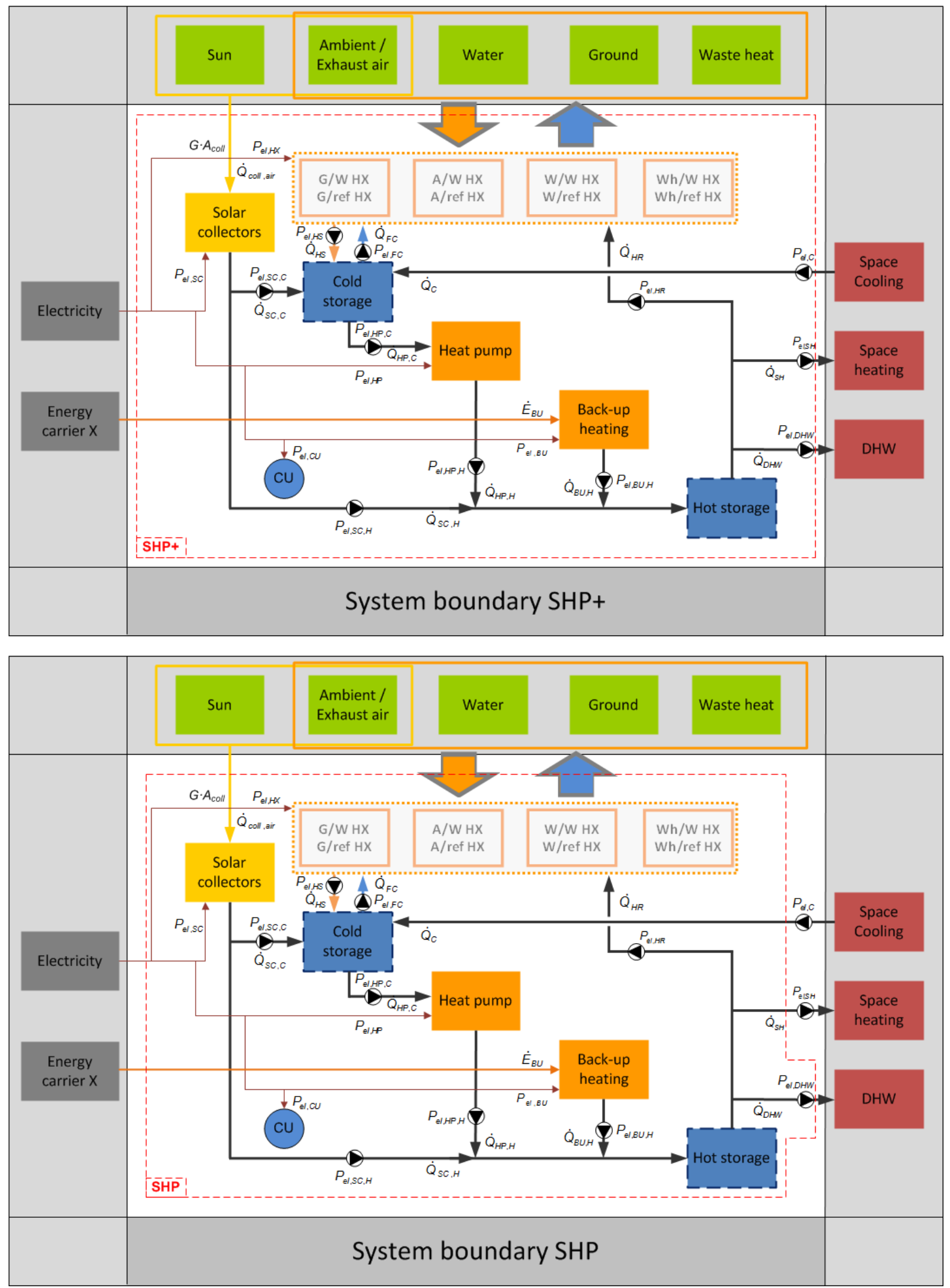

Figure 3-3 - Main system boundaries for the reference SHP system for heating and cooling applications: SHP+ system boundary (top) and SHP system boundary (bottom) 
In the system boundaries bSt - Before Storage (Figure 3-4) a distinction between the Heating Operation Mode (HOM) and Cooling Operation Mode (COM) is made, as previously discussed. All useful energy outputs of the SHP system to the energy storages are taken into account. Thus, the storage losses, as well as the energy needed to supply the heat to the storages are not included. However, depending on the operation mode of the system, the function of the storages and the driving energy input to the system might vary. For example, in heating operation mode, the cold storage is included in the system, since it is a part of the heat source for the heat pump. If switched to the cooling operation mode, the cooling load is supplied from the cold storage, which then has to be excluded from the energy balance. Hence, for systems capable of operating in several modes over the considered measurement or simulation period, the system boundaries have to change respectively. This is not a substantial limitation, since most of the SHP systems described within Task 44 / Annex 38 are designed primarily or solely for these applications. Nevertheless, the possibility to consider cooling operation mode is also given.

Within the system boundaries HP+HS (HP+HR) - Heat Pump with Heat Source (Heat pump with Heat Rejection), Figure 3-5, the subsystem including heat pump unit with all its heat sources or heat sinks, which can also include another heat transforming unit (here the solar collector), is balanced. As for the previous system boundaries (bSt), different operation modes have to be considered separately because of different resulting boundaries. In the space heating and DHW operation mode the useful energy output considered is the gross energy output of the heat pump only, not taking into account losses due to short or long term storage, piping etc. The energy input to the system includes the overall input needed both for the heat pump and the considered solar thermal parts. If the solar collectors do not interact with the heat pump directly (e.g. direct evaporation in the collector) or indirectly (e.g. feeding into the heat source of the heat pump - ground, low temperature storage etc.), then it should be excluded from the calculations. The overall system control unit is not included in the energy balance, since only the heat pump system is considered. However, if the heat pump does not have an additional control unit, the consumption of the central one should be included appropriately. 

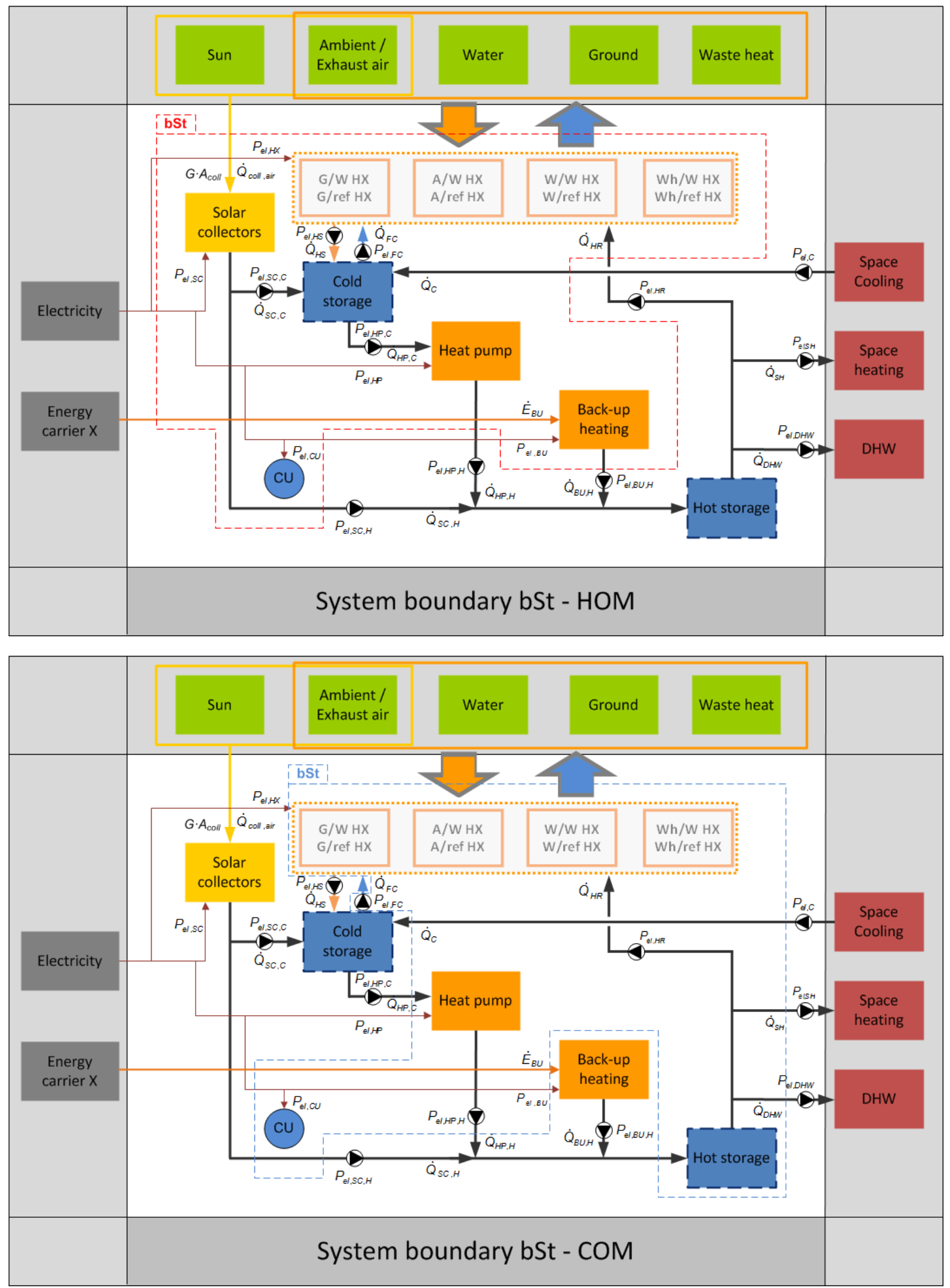

Figure 3-4 - Main system boundaries for the reference SHP system for heating and cooling applications: bSt system boundary for heating operation mode (top) and bSt system boundary for cooling operation mode (bottom) 

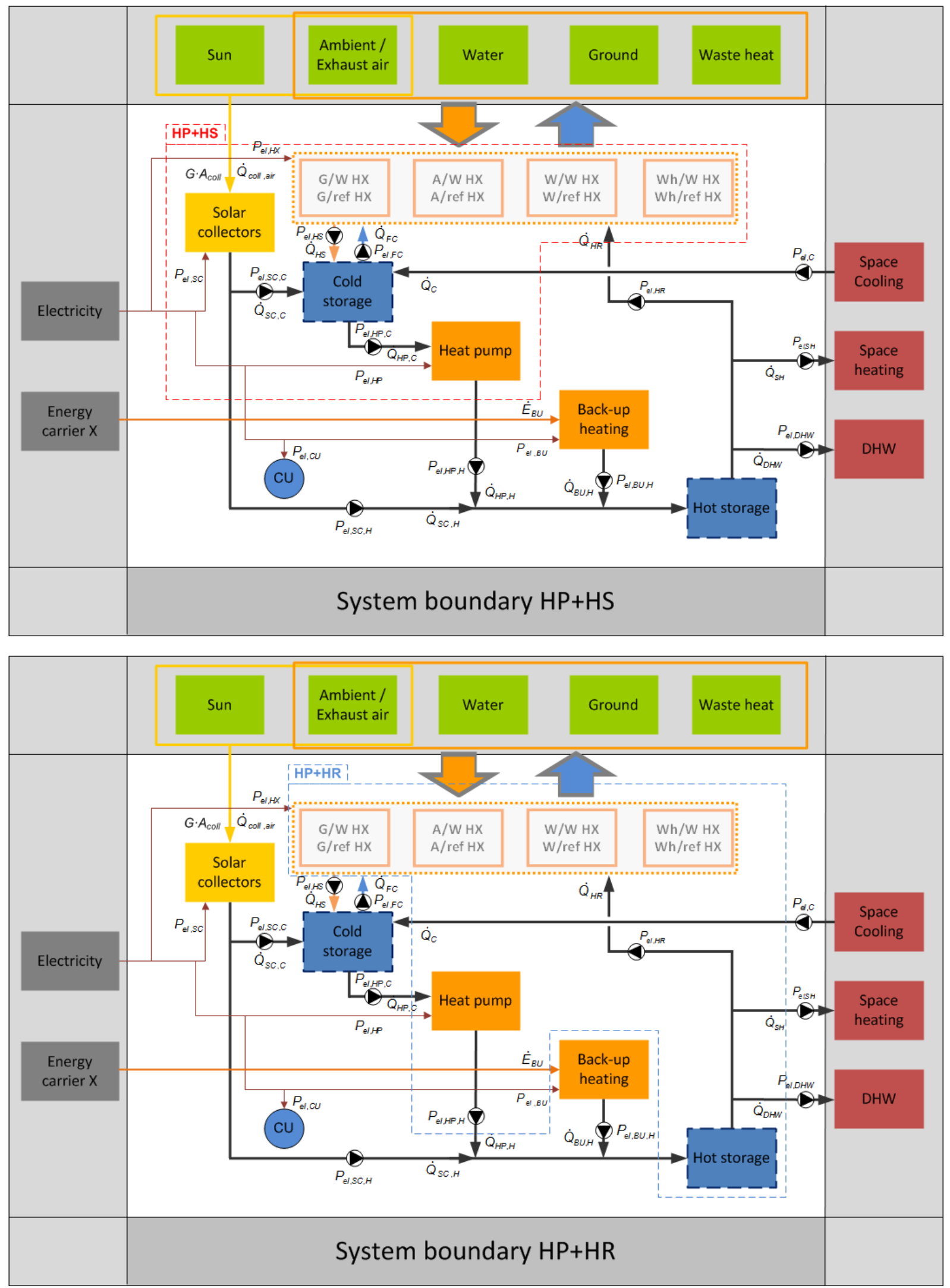

Figure 3-5 - Main system boundaries for the reference SHP system for heating and cooling applications: $H P+H S$ system boundary (top) and HP+HR system boundary (bottom) 


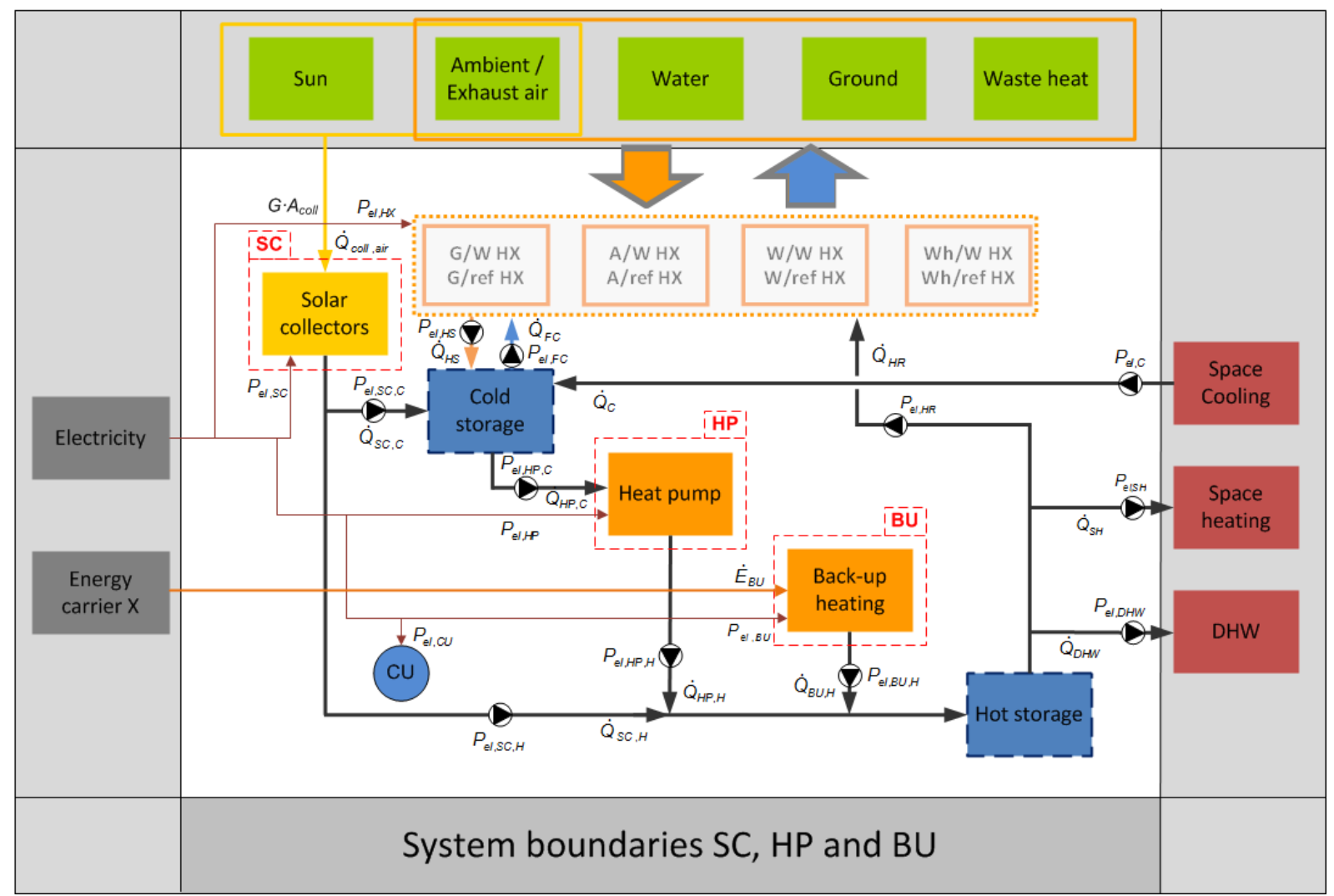

Figure 3-6 - Main system boundaries for the reference SHP system for heating and cooling applications: SC, HP and $B U$ system boundaries

In the system boundary HP - Heat Pump (Figure 3-6), the consumed electricity includes supporting systems like controls, crankcase heaters etc., for the entire measurement or simulation period, including stand-by periods. It is similar to the one currently used for the definition of the COP and SCOP in a number of European standards. There, the energy inputs and outputs are often corrected as described in e.g. EN 14511 (see chapter 4.1.1). If used for a performance figure calculated from the field trial results, the energy output will generally not be corrected due to considerable effort needed to obtain all measurement data needed.

The performance figures for the Back-Up Unit (BU) will generally depend on the technology of the applied device. Figures for Solar Collector (SC) efficiency can be found in standards and guidelines and are briefly discussed in chapter 4 . Note that $P_{e l, S C}$ considers only direct energy consumption of the solar collector like a fan for hybrid collectors. For standard solar collectors $\mathbf{S C}$ is not defined as the energy consumption for the circulation pump $P_{e l, S C, H}$ is not considered. 


\section{Definition of performance figures}

Efficiency is one of the main performance indicators for heating and cooling systems and is generally defined as the ratio between the useful energy output from the system to the energy input to the system. The energy input is commonly limited to the driving energy needed to transform the primary (including environmental) and/or final energy into useful energy and deliver it to the end user. As already pointed out previously, depending on the aim of the performance assessment of an energy conversion system, the interesting aspects might be for instance economy, environment or energy related evaluation of the system operation. In this chapter, the energy related evaluation of system performance will be discussed; the environmental aspects will be highlighted in chapter 5 .

The efficiency of a heating or a cooling system which is, in general, an energy conversion system using one or more driving energy inputs to produce heating and/or cooling effect or useful energy output, is expressed as a ratio of these energy flows to and from the system, equation 2. Note that even though in cooling applications the removed energy form the user is added to the cooling system, this energy is still regarded as a "useful energy output" of the system and positive values are used in the equations.

$$
\eta_{s y s}=\frac{\sum_{i=1}^{n} Q_{o u t, i}}{\sum_{j=1}^{m} Q_{i n, j}}=\frac{Q_{o u t}}{Q_{i n}}
$$

$Q_{\text {out }}$ contains the considered useful energy provided by the system while $Q_{\text {in }}$ represents the sum of all considered energy inputs to the system during the chosen time period. As discussed in chapter $3, Q_{\text {out }}$ and $Q_{\text {in }}$ will generally differ depending on the choice of system boundaries yielding generally different definitions of performance figures.

Another distinction that can be made between different performance figures is according to the operating conditions under which they were determined. For heat pumps, as for other energy conversion units, a distinction between steady-state operating conditions, mostly provided under controlled laboratory conditions, and transient conditions immanent to real operating environments in the field is often made. As described in deliverable B3, a trend toward transient measurement under controlled laboratory conditions, especially for complex systems, could be observed at the time of writing this report. Beside the time profile of the operating conditions, it is essential to give information on other parameters like heat sink or heat source temperature levels for the heat pump or solar irradiation levels for the collector to provide full information to the user. By just stating a performance figure without the conditions under which it was determined, room for misinterpretation is given.

A difference between the component and system performance figures is often being made. In many cases, however, this difference is arbitrary and depends on the definition of the system boundaries. Thus, for example, as a compressor can be a component of a heat pump unit, the heat pump unit can represent a component of a SHP system. In the following text, the heat pump unit, solar collector or the back-up unit will be regarded as components parts of a SHP system or one of its subsystems.

It is also necessary to exactly define the "energy quality" involved in the calculation. By the energy quality the primary energy content of the energy input or the energy output is meant. Very often, the terms primary energy or useful energy are quite arbitrary. Therefore, a clear 
definition for these and some other terms are needed. This will be discussed in chapter 5 , where environmental performance evaluation is addressed.

\subsection{Component performance figures}

\subsubsection{Coefficient of Performance - COP}

The COP of the heat pump is the ratio between its heating capacity and the overall electricity consumption, both measured under steady-state operating conditions. The counterpart of the $C O P$ for cooling applications is the Energy Efficiency Ratio $(E E R)$. The system boundary for the energy balancing corresponds to boundary HP in Figure 3-6. Hence, the COP can be calculated as:

$$
C O P=\frac{\overline{\dot{Q}}_{H P, H}}{\bar{P}_{e l, H P}}
$$

In European Standards (e.g. EN 14511-3 or EN 15879-1), the heating (or cooling) capacity for hydronic distribution systems is corrected for the (assumed) amount of energy dissipated from the liquid circulation pump to the heat transfer fluid. The corrective amount of heat is calculated from the measured pressure drop over the heat exchanger and assumed circulation pump efficiency. The electricity consumption due to pumping work needed to overcome the pressure losses of the heat transfer fluid within the heat pump unit is corrected for the same amount of energy.

\subsubsection{Seasonal Coefficient of Performance - SCOP}

The SCOP (and its counterpart for the cooling applications - SEER) are efficiency figures calculated from the laboratory measurement data by assuming defined time-dependent operating conditions over a certain period of time. The time dependency considers in general oscillating ambient and heat source temperatures, changing heat supply temperatures, operation under part-load conditions etc. The system boundary is the same as for the COP boundary HP in Figure 3-6.

According to current version of the European Standard EN 14825, the SCOP and the SEER are calculated using the temperature bin method. This method is based on the division of the cumulative annual frequency of the outside dry-bulb temperature into temperature classes called bins. For every bin, an average operating condition is defined. It is then assumed, that the heat pump unit operates under this condition for the entire temperature range covered by the bin. Finally, the energy inputs, including stand-by consumption, as well as useful energy outputs over all bins are summed up and the efficiency is calculated. A full description of the method, as well as some open questions can be found e.g. in Wemhöner and Afjei (2003).

Within EN 14825, the SCOP and the SEER are defined as follows - equations 4 and 5: 


$$
\begin{gathered}
S C O P=\frac{Q_{h}}{\frac{Q_{h}}{S C O P_{o n}}+Q_{e l, o f f}} \\
S E E R=\frac{Q_{C}}{\frac{Q_{C}}{S E E R_{o n}}+Q_{e l, o f f}}
\end{gathered}
$$

In the above equations, $Q_{h}$ and $Q_{C}$ represent the annual heating and cooling loads, respectively. $S C O P_{\text {on }}$ and $S E E R_{\text {on }}$ are the figures representing efficiencies only for the periods of operation when the heat pump unit and in case of $S C O P_{\text {on }}$ the direct electrical back-up heating are delivering / extracting useful energy. $Q_{e l, \text { off }}$ is the electricity consumption of the unit in idle state, e.g. in stand-by mode.

\subsubsection{Solar collector efficiency}

The stationary collector efficiency is expressed as the thermal output of the collector $\dot{Q}_{\text {gain }}$ divided by the irradiance $G_{g}$ on the collector pane $A_{\text {coll, }}$ equation 6:

$$
\eta_{\text {Col }}=\frac{\dot{Q}_{\text {gain }}}{G_{g} \cdot A_{\text {coll }}}
$$

Standards (e.g. EN 12975-2) define the standard testing conditions, e.g. minimal values for irradiance, ambient air temperature, wind speed and the test procedure (steady-state or transient). For covered collectors the steady state collector efficiency is described as quadratic equation depending on the temperature difference between collector mean fluid temperature and ambient air temperature. For uncovered collectors the stationary collector efficiency is described as linear equation regarding the temperature difference and considers wind speed and sky temperature for long-wave irradiance losses.

The efficiency of the solar thermal system is defined as the ratio of the obtained useful heat divided by the irradiation (see e.g. VDI 6002-1 (2004)) on the collector pane. Depending on how the useful heat is defined and where it is measured, stagnation periods, pipe losses, actual weather conditions and interdependency to the conventional heating system may be taken into account Thus, using the nomenclature of this report for the useful heat, the collector utilisation ratio $\omega_{S C}$ may be defined as (equation 7 ):

$$
\omega_{S C}=\frac{Q_{S C, H}}{\int G_{g} \cdot A_{\text {Coll }} \cdot d t}
$$

Analogously to heat pump systems, a seasonal performance factor can also be defined, equation 8. Attention has to be paid that within Task 44 / Annex $38 P_{e l, S C}$ considers only direct energy consumption of the solar collector like a fan for hybrid collectors. For standard 
solar collectors $S P F_{S C}$ is not defined as the energy consumption for the circulation pump $P e l, S C, H$ is not considered.

$$
S P F_{S C}=\frac{Q_{S C, H}}{\int P_{e l, S C} \cdot d t}
$$

\subsection{System performance figures}

\subsubsection{Seasonal Performance Figure - SPF}

In reviewed normative documents and in common practice, Seasonal Performance Factor is mainly used as a system performance figure, although in some cases it can be also used to express the efficiency of a heat pump unit (e.g. in VDI 4650). The SPF gives the final energy efficiency of the whole system or a defined subsystem, calculated as the overall useful energy output to the overall driving final energy input for an adopted system boundary, equation 9. It expresses the performance of a system over a year or a season - a heating or a cooling season, for example. The same definition can also be used for shorter time periods, such as a week or a month, but a different nomenclature for the figure has to be used - i.e. weekly performance figure.

$$
S P F=\frac{\int\left(\dot{Q}_{S H}+\dot{Q}_{D H W}+\dot{Q}_{C}\right) \cdot d t}{\int \sum P_{e l} \cdot d t}
$$

Beside an overall SPF which provides the efficiency of the system in all operation modes, separate SPFS for single operation modes (e.g. heating only, heating and DHW, cooling and DHW) can be defined. However, if e.g. heating and cooling or heating and DHW are produced simultaneously, it might be difficult to quantify the specific input and/or output energy for a single mode of operation. This has to be taken into account when evaluating the measurement or simulation results. Although the useful cooling energy removed from the system surrounding $Q_{C}$ has the opposite algebraic sign than the useful heating energy supplied by the system $\left(Q_{S H}+Q_{D H W}\right)$ in the physical sense, for the definition of the performance figures throughout the document $Q_{C}$ is treated as a useful energy output of the system in the engineering manner, i.e. positive values are to be used in the equations, as it is commonly done in engineering praxis.

The SPF quantifies the efficiency of a system or a subsystem for given operating conditions - heat source temperature, solar irradiation, supply temperature profile etc. Final electrical energy provided on site is considered as energy input. This does not take into consideration the "quality" of the driving energy, e.g. in terms of the depletion of non-renewable resources or greenhouse gas emissions caused during the lifetime of a system. For such an environmental performance of the system, available energy mixes on site have to be taken into account. For that reason, Primary Energy Ratio for non-renewable part of energy input $\left(P E R_{N R E}\right)$ and Equivalent Warming Impact of the System $\left(E W I_{s y s}\right)$ are introduced, chapter 5.

Note that for non-monoenergetic systems (e.g. if the back-up heating system runs on biomass, gas etc.), the SPF cannot fully reflect the total energy consumption, since it considers only electricity as energy input, as defined for SHP systems. In that case, the consumption of any additional fuel should be given separately and the overall system performance expressed by the primary energy ratio PER. 
Also note that for air-source heat pumps, defrosting has to be considered:

- Direct electric defrosting: Electricity consumption should be included in $P_{e l, H P}$;

- Hot gas defrosting: The energy consumption should also be included in $P_{e l, H P}$;

- Reverse cycle defrosting: the heat energy taken from the storage/building has to be subtracted from the useful energy output at the appropriate boundary, if not automatically executed by the heat meter.

Applied to the system boundaries defined in previous chapter - Figure 3-3 through Figure 3-6 - the following SPFs can be defined (equations 10-18).

As stated in previous chapter, for boundaries bSt and HP+HS (HR), separate SPFs for heating (HOM) and cooling (COM) operation modes have to be defined. Note that Table 3-2 has to be considered for the assessment of electricity consumption for the distribution of DHW $-P_{e l, D H W}$. 


\begin{tabular}{|c|c|c|}
\hline SHP+ & $\begin{array}{l}S P F_{S H P_{+}}=\frac{\int\left(\dot{Q}_{S H}+\dot{Q}_{D H W}+\dot{Q}_{C}\right) \cdot d t}{\int\left(\sum P_{e l, S H P+}\right) \cdot d t} \\
\qquad P_{e l, S H P+}=P_{e l, S C}+P_{e l, S C, C}+P_{e l, S C, H}+P_{e l, H P}+P_{e l, H P, C}+P_{e l, H P, H}+P_{e l, H S}+P_{e l, B U}+ \\
\quad+P_{e l, B U, H}+P_{e l, S H}+P_{e l, D H W}+P_{e l, C}+P_{e l, F C}+P_{e l, H R}+P_{e l, H X}+P_{e l, C U}\end{array}$ & [10] \\
\hline SHP & $\begin{array}{c}S P F_{S H P}=\frac{\int\left(\dot{Q}_{S H}+\dot{Q}_{D H W}+\dot{Q}_{C}\right) \cdot d t}{\int\left(\sum P_{e l, S H P}\right) \cdot d t} \\
\sum P_{e l, S H P}=P_{e l, S C}+P_{e l, S C, C}+P_{e l, S C, H}+P_{e l, H P}+P_{e l, H P, C}+P_{e l, H P, H}+P_{e l, H S}+P_{e l, B U}+ \\
\quad+P_{e l, B U, H}+P_{e l, F C}+P_{e l, H R}+P_{e l, H X}+P_{e l, C U}+P_{e l, D H W}\end{array}$ & [11] \\
\hline $\begin{array}{c}\text { bSt } \\
\text { (HOM) }\end{array}$ & $\begin{aligned} S P F_{b S t, H O M} & =\frac{\int\left(\dot{Q}_{S C, H}+\dot{Q}_{H P, H}+\dot{Q}_{B U, H}\right) \cdot d t}{\int\left(\sum P_{e l, b S t, H O M}\right) \cdot d t} \\
\sum P_{e l, b S t, H O M} & =P_{e l, S C}+P_{e l, S C, C}+P_{e l, H P}+P_{e l, H P, C}+P_{e l, H S}+P_{e l, F C}+P_{e l, B U}+ \\
& +P_{e l, H X}+P_{e l, C U}\end{aligned}$ & [12] \\
\hline $\begin{array}{c}\text { bSt } \\
\text { (COM) }\end{array}$ & $\begin{array}{l}S P F_{b S t, C O M}=\frac{\int\left(\dot{Q}_{H P, C}+\dot{Q}_{F C}\right) \cdot d t}{\int\left(\sum P_{e l, b S t, C O M}\right) \cdot d t} \\
\quad \sum P_{e l, b S t, C O M}=P_{e l, H P}+P_{e l, H P, H}+P_{e l, H R}+P_{e l, H X}+P_{e l, C U}\end{array}$ & [13] \\
\hline $\mathrm{HP}+\mathrm{HS}$ & $S P F_{H P+H S}=\frac{\int \dot{Q}_{H P, H} \cdot d t}{\int\left(P_{e l, H P}+P_{e l, H P, C}+P_{e l, S C}+P_{e l, S C, C}+P_{e l, H S}+P_{e l, H X}+P_{e l, F C}\right) \cdot d t}$ & [14] \\
\hline $\mathrm{HP}+\mathrm{HR}$ & $S P F_{H P+H R}=\frac{\int \dot{Q}_{H P, C} \cdot d t}{\int\left(P_{e l, H P}+P_{e l, H P, H}+P_{e l, H R}+P_{e l, H X}\right) \cdot d t}$ & [15] \\
\hline HP & $S P F_{H P}=\frac{\int\left(\dot{Q}_{H P, H}+\dot{Q}_{H P, C}\right) \cdot d t}{\int P_{e l, H P} \cdot d t}$ & [16] \\
\hline $\begin{array}{c}\text { HP } \\
\text { (HOM) }\end{array}$ & $S P F_{H P, H O M}=\frac{\int \dot{Q}_{H P, H} \cdot d t}{\int P_{e l, H P, H O M} \cdot d t}$ & [17] \\
\hline $\begin{array}{c}\mathrm{HP} \\
(\mathrm{COM})\end{array}$ & $S P F_{H P, C O M}=\frac{\int \dot{Q}_{H P, C} \cdot d t}{\int P_{e l, H P, C O M} \cdot d t}$ & [18] \\
\hline
\end{tabular}




\subsection{Other performance figures}

\subsubsection{Solar fraction}

The solar fraction specifies the share of energy delivered to the thermal storage by the solar part of the system. Both the solar contribution and the overall output of the system need to be precisely defined. For solar and heat pump systems only the direct solar heat delivered to the conventional part of the system is accounted for as solar heat. Some definitions exist in several standards and publications, which vary in the treatment of the thermal losses of the heat storage.

The first definition from ISO 9488 (ISO, 2001) or EN 12976-2 (EN, 2006) calculates the ratio of the direct solar heat to the useful heat, equation 19. The storage losses are not considered in that case, which results in the highest values for the solar fraction. In solar active houses with a large storage volume on the heat sink side, very high solar fractions of 1 or even higher could be achieved. However, this does not mean that no additional heat is needed. Higher storage losses increase the demand for direct solar heat as well as for additional heat, which leads to higher solar fractions.

$$
f_{\text {sol, } 1}=\frac{Q_{S C, H}}{Q_{D H W}+Q_{S H}}
$$

Contrary to the first definition, in the second one (see e.g. Kramer et al., 2013) all thermal losses of the storage are subtracted from the direct solar heat, leading to very low values of solar fraction, equation 20. In this case, it is limited to 1 , reached when no additional heat is delivered. It can also become negative when the losses exceed the solar contributions for small scale systems. Higher storage losses that increase the need for additional heat lead to lower solar fractions.

$$
f_{s o l, 2}=\frac{Q_{S C, H}-Q_{L}}{Q_{D H W}+Q_{S H}}=1-\frac{Q_{H P, H}+Q_{B U, H}}{Q_{D H W}+Q_{S H}}
$$

The third definition comes from VDI 6002-1 (VDI 6002-1, 2004). In this definition only the solar quota of the storage losses are subtracted from the direct solar heat and then related to the useful heat, equation 21. The definition can be transformed to the ratio of direct solar heat to the total heat production, thus the sum of direct solar heat and all other heat inputs from the system. If there is no additional heat input, the solar fraction becomes 1 . Increasing the storage losses leads to a moderate rise of the solar fraction.

$$
f_{s o l, 3}=\frac{Q_{S C, H}-Q_{L} \cdot \frac{Q_{S C, H}}{Q_{H P, H}+Q_{S C, H}+Q_{B U, H}}}{Q_{D H W}+Q_{S H}}=\frac{Q_{S C, H}}{Q_{H P, H}+Q_{S C, H}+Q_{B U, H}}
$$

The deviations between the three definitions become obvious for a solar active house with a big hot water storage. Figure 4-1 shows the solar fractions for a simulation study according to Task 32 boundary conditions (Heimrath and Haller (2007)). It is a single family house in Zurich with a space heating demand of $60 \mathrm{kWh} /\left(\mathrm{m}^{2} \cdot \mathrm{a}\right)$ and a hot water draw of $200 \mathrm{l} / \mathrm{d}$ at $45^{\circ} \mathrm{C}$. The collector area of $30 \mathrm{~m}^{2}$ is kept constant while the storage volume rises from 1 to $25 \mathrm{~m}^{3}$. Storage losses, conventional heat and solar heat increase with storage size. 


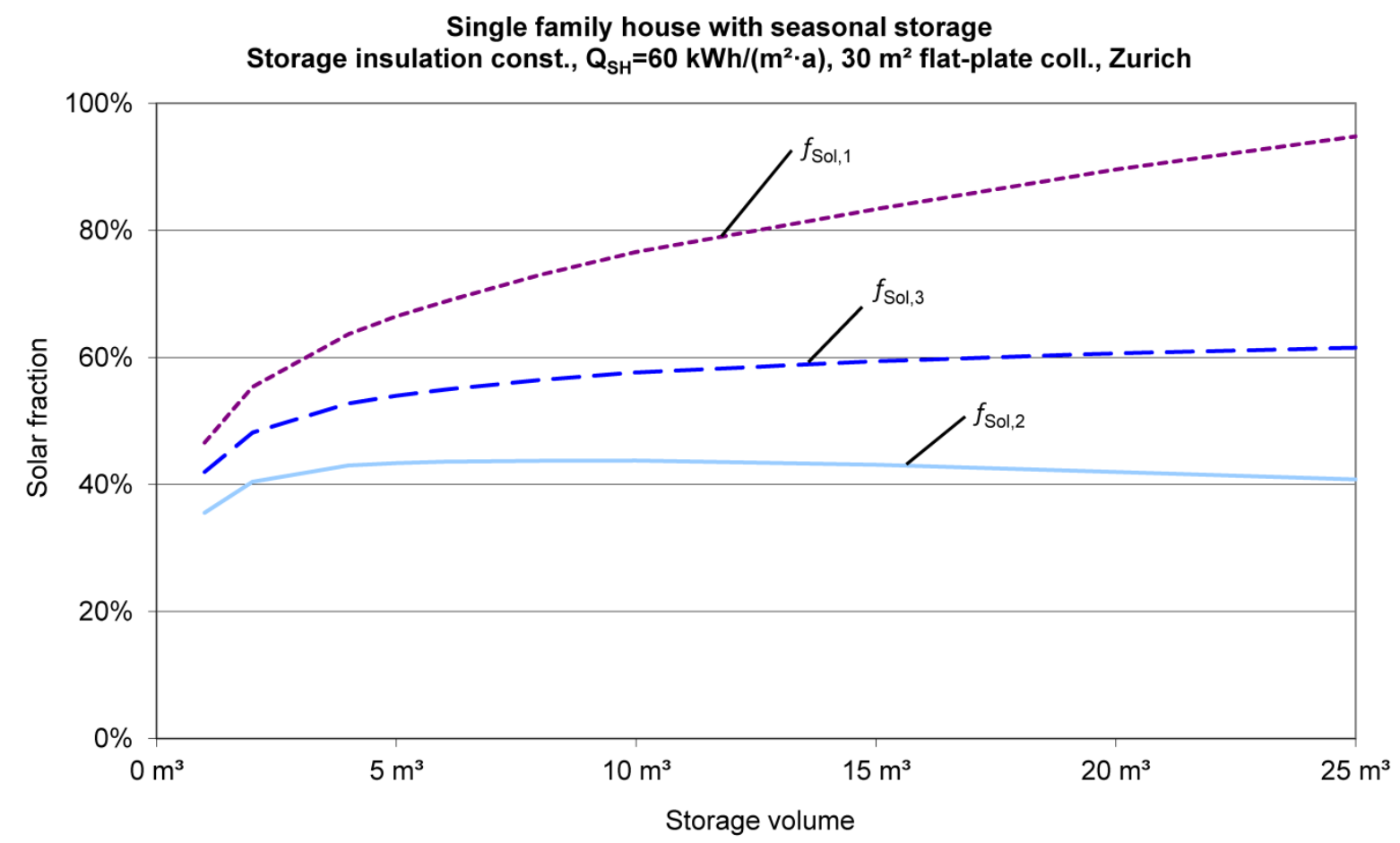

Figure 4-1 Different definitions of the solar fraction of a solar active house

Different definitions for solar fraction yield different values and show principally different trends with increasing storage volume, Figure 4-1. While $f_{s o, 2}$ shows an optimal size of the storage volume focusing on the conventional heat consumption, the solar fractions calculated according to the last two definitions $\left(f_{s o l, 1}\right.$ and $\left.f_{s o l, 3}\right)$ increase with storage size. As $f_{s o l, 1}$ is not limited to $100 \%$, it rises very steeply over the storage volume.

\subsubsection{Renewable heat fraction}

An SHP system can generally use more than one renewable energy source. Beside direct usage of solar energy, as previously described, the heat pump may use energy from the ambient air, ground, ground water or the solar part of the system as the heat source. In this context, the solar fraction does not reflect the full potential of the system to use renewable energy sources and can thus be seen as a less important figure.

Instead, the Renewable Heat Fraction can be defined, equation 22.

$$
f_{\text {ren,SHP }}=1-\frac{\int\left(\sum P_{e l, S H P}\right) \cdot d t}{Q_{D H W}+Q_{S H}} \hat{=} 1-\frac{1}{S P F_{S H P}}
$$

As the renewable heat fraction can be derived from the SPF it is therefore important to put the system boundary to the index.

\subsubsection{Fractional energy savings}

The fractional energy savings describe the influence of a specific optimization like the combination with a solar thermal system in relation to a reference system. The choice of the reference system with its properties has a big influence on this performance figure. Penalties, which eventually occur, are added to the electricity consumption of the solar assisted system. 
See Deliverables of Subtask $C$ for their calculation. The system boundary needs to be specified e.g. here SHP. Penalties for the reference system should actually be zero otherwise they need to be added to the electricity consumption of the reference system.

$f_{\text {sav }, S H P}=1-\frac{\left(Q_{\text {el }, S H P}+Q_{\text {Penalty }}\right)_{\text {solar }}}{\left(Q_{\text {el,SHP }}\right)_{\text {ref }}}=1-\frac{\left(S P F_{S H P}\right)_{\text {ref }}}{\left(S P F_{S H P}\right)_{\text {solar }}}$

This figure applies only for mono-energetic systems. If there is another energy carrier than electricity e.g. for the back-up heater the primary energy factors have to be taken into account. See chapter 5.1.3 for fractional primary energy savings. 


\section{Environmental evaluation of SHP systems}

In order to compare systems and technologies in terms of their environmental impact, two main performance figures are recommended in this report:

- Primary Energy Ratio of non-renewable energy sources - PER $R_{N R E}$

- Equivalent Warming Impact of the SHP system - EWI sys

$\boldsymbol{P E} \boldsymbol{R}_{\text {NRE }}$ gives information on the consumption of non-renewable energy sources for the provision of useful energy output of the system. Note that it does not account for the production, distribution, installation and end-of-life disposal of the SHP unit or system itself. It is a figure which considers the depletion of limited energy resources contained in e.g. fossil fuels. It is defined as the ratio of the useful energy output of the system to the primary energy input.

$E W_{\text {sys }}$ is the ratio of the greenhouse gas emission to the useful energy output of the system. The greenhouse gas emission is expressed as equivalent $\mathrm{CO}_{2}$ emission for the provision of the energy carrier on installation site (final energy) and its consumption.

For the calculation of these two figures, the following indicators are needed:

- $C E D_{N R E}$ - Cumulative Energy Demand (CED), non-renewable: It quantifies the nonrenewable primary energy used to provide the final energy, including the energy used for construction of the electric grid and power plants. This indicator accounts for the primary energy from fossil, nuclear and primary forest resources (i.e. original forests that are destroyed and replaced by farmland) defined in terms of primary energy to final energy $\mathrm{kWh}_{\mathrm{PE}} / \mathrm{kWh}$

- $G W P_{e c}$ - Global Warming Potential is the weighted addition of the emission of different greenhouse gases when providing final energy, including emissions generated during construction of the electric grid and power plants. It does not take into account refrigerant leakage during the system operation. It is expressed in terms of equivalent quantity of carbon dioxide per quantity final energy $\left(\mathrm{kg}_{2} \mathrm{CO}_{2} \mathrm{eq} / \mathrm{kWh} \mathrm{FE}_{\mathrm{FE}}\right)$ for a time frame of 100 years. Please note that the $\mathrm{GWP}_{\mathrm{ec}}$ as defined here differs from the GWP used to quantify the influence of the various substances when released into the atmosphere on the global warming phenomena (as defined e.g. in EU (2006)).

Since the provenance of the electrical energy at the plug varies widely from country to country due to their power generation and import mixes, it is important to define reference values for comparison purposes. For the electrical energy, the corresponding European electricity supply mix (ENTSO-E - European Network of Transmission System Operators for Electricity) on low voltage level for these two indicators was chosen from Itten et al. (2012). They include electricity production, transmission and distribution including corresponding losses. In certain cases, however, it is favourable to use specific national values, which may differ substantially between the countries. These values can be found in e.g. Itten et al. (2012). For transnational comparisons, values from Table 5-1 are recommended.

For all other energy carriers, the values for each country are nearly identical and are taken from the Ecoinvent database (Ecoinvent (2013)) that contains a large number of processes for production of goods and provision of services with a focus on European production chains, see Table 5-1.

Subsequently, these values will be used to define the Primary Energy Ratio, non-renewable $\left(P E R_{N R E}\right)$ and the $E W I_{s y s}$ factor for each investigated system. 
Table 5-1 - CED NRE and GWP for different energy carriers. Source: Itten et al. (2012), Ecoinvent (2013)

\begin{tabular}{|c|c|c|}
\hline Energy carrier & $\begin{array}{c}\text { CED } \\
{\left[k W h_{\mathrm{PE}} / k W h_{\mathrm{FE}}\right]}\end{array}$ & $\begin{array}{c}\mathrm{GWP}_{\mathrm{ec}}{ }^{*} \\
{\left[\mathrm{~kg} \_\mathrm{CO}_{2} \text { eq } / \mathrm{kWh}_{\mathrm{FE}}\right]}\end{array}$ \\
\hline Electricity & 2.878 & 0.521 \\
\hline Gas & 1.194 & 0.307 \\
\hline Oil & 1.271 & 0.318 \\
\hline \multicolumn{3}{|l|}{ Wood } \\
\hline logs & 0.030 & 0.020 \\
\hline pellets & 0.187 & 0.041 \\
\hline chips & 0.035 & 0.011 \\
\hline \multicolumn{3}{|c|}{$\begin{array}{l}\text { * Please note that the } \mathrm{GWP}_{\mathrm{ec}} \text { as defined here differs from the } \\
\text { GWP used to quantify the influence of the various substances } \\
\text { when released into the atmosphere on the global warming } \\
\text { phenomena (as defined e.g. in EU (2006). }\end{array}$} \\
\hline
\end{tabular}

\subsubsection{Primary Energy Ratio - PER $R_{\mathrm{NRE}}$}

To relate the useful energy output to the non-renewable primary energy consumption, the Primary Energy Ratio $\left(P E R_{N R E}\right)$ is defined with the unit $\mathrm{kWh} \mathrm{h}_{\mathrm{UE}} / \mathrm{kWh}_{\mathrm{PE}}$.

For an electric system, it is calculated using equation 24 :

$$
P E R_{N R E}=\frac{\int\left(\dot{Q}_{S H}+\dot{Q}_{D H W}+\dot{Q}_{C}\right) \cdot d t}{\int \sum\left(P_{e l} \cdot C E D_{N R E, e l}\right) \cdot d t}
$$

where $P_{\text {el,final, }}$ is the total electricity consumption of the system during operation.

By introducing the definition of the SPF (equation 9), it can be transformed to:

$$
P E R_{N R E}=\frac{S P F_{S H P}}{C E D_{N R E, e l}}
$$

For systems using different primary energy sources, this factor is calculated as:

$$
P E R_{N R E}=\frac{\int\left(\dot{Q}_{S H}+\dot{Q}_{D H W}+\dot{Q}_{C}\right) \cdot d t}{\int \sum_{i=\text { energy source }}\left(\dot{Q}_{F E} \cdot C E D_{N R E, i}\right) \cdot d t}
$$

where $Q_{\text {final, }}$ is the final energy consumption of the system during operation and expressed in $\mathrm{kWh}_{\mathrm{FE}}$.

In some cases, the reciprocal value of $P E R_{N R E}$ - Primary Energy Effort Figure (PEEF) can be useful:

$$
\operatorname{PEEF}_{N R E}=\frac{\int \sum_{i=\text { energysource }}\left(\dot{Q}_{F E, i} \cdot C E D_{N R E, i}\right) \cdot d t}{\int\left(\dot{Q}_{S H}+\dot{Q}_{D H W}+\dot{Q}_{C}\right) \cdot d t}=\frac{1}{P E R_{N R E}}
$$


5.1.2 Equivalent Warming Impact - $\mathrm{EWI}_{\text {sys }}$

Similarly to equation 25 , the $E W I_{\text {sys }}$ factor $\left[\mathrm{kg}_{-} \mathrm{CO}_{2} \mathrm{eq} / \mathrm{kWh}\right.$ UE for an electric system can be defined as:

$E W I_{s y s}=\frac{G W P_{e l}}{S P F_{S H P}}$

For systems using other primary energy sources, this results in:

$E W I_{s y s}=\frac{\int \sum_{i=\text { energysource }}\left(\dot{Q}_{F E, i} \cdot G W P_{e c, i}\right) \cdot d t}{\int\left(\dot{Q}_{S H}+\dot{Q}_{D H W}+\dot{Q}_{C}\right) \cdot d t}$

\subsubsection{Fractional primary energy savings}

Using the formulations form the previous chapter, fractional energy savings can be defined for the SHP system. If there is more than one energy carrier in the system the fractional energy savings have to be related to the primary energy. All final energy consumptions have to be multiplied with the primary energy factors, equation 30 . Furthermore it is important also to specify the system boundary (here: SHP).

$$
f_{\text {sav }, S H P, P E}=1-\frac{\left(\sum_{i=\text { energysource }}\left(\dot{Q}_{F E, i} \cdot C E D_{N R E, i}\right)\right)_{S H P}}{\left(\sum_{i=\text { energy source }}\left(\dot{Q}_{F E, i} \cdot C E D_{N R E, i}\right)\right)_{\text {ref }}}
$$

\subsubsection{Fractional $\mathrm{CO}_{2}$-emission savings}

Equivalently to chapter 5.1.3, the fractional $\mathrm{CO}_{2}$-emission savings can be defined, equation 31 . These are balanced according to the system boundary SHP.

$f_{\text {sav }, \text { SHP }, \text { emission }}=1-\frac{\left(\sum_{i=\text { energysource }}\left(\dot{Q}_{F E, i} \cdot G W P_{e c, i}\right)\right)_{S H P}}{\left(\sum_{i=\text { energysource }}\left(\dot{Q}_{F E, i} \cdot G W P_{e c, i}\right)\right)_{\text {ref }}}$ 


\section{References}

Anderson, J.V., Mitchell, J.W., Beckman, W.A (1980) A Design Method for Parallel SolarHeat Pump Systems. Solar Energy Vol. 25, 155-163

Ecoinvent (2013) Ecoinvent - International Database for Life Cycle Inventory data. Swiss Center for Life cycle Inventories, Dübendorf. http://www.ecoinvent.org/database/ (25.06.2013)

EU (2009) Directive 2009/125/EC of the European Parliament and of the Council of 21 October 2009 establishing a framework for the setting of ecodesign requirements for energyrelated products (recast). Official Journal of the European Union, L 285 pp 10-35, 31.10.2009

Frank, E., Haller, M.Y., Herkel, S., Ruschenburg, J. (2010) Systematic classification of combined solar thermal and heat pump systems. Eurosun Conference, Graz, Austria

Haller, M. Y., Haberl, R., Mojic, I., Frank, E. (2013) Hydraulic integration and control of heat pump and combi-storage: Same components, big differences. Proceedings of the International Conference on Solar Heating and Cooling for Buildings and Industry, September 23-15, 2013, Freiburg, Germany

Heimrath R. und Haller M. Y. (2007) Project Report A2 of Subtask A: The Reference Heating System, the Template Solar System. Institut für Wärmetechnik, Graz University of Technology, Austria

Itten, R., Frischknecht, R., Stücki, M. (2012) Life Cycle Inventories of Electricity Mixes and Grid. ESU-service (PSI), July 2012.

Kramer, K. and Helmers, H. (2013) The interaction of standards and innovation: Hybrid photovoltaic-thermal collectors. Solar Energy Vol. 98, 434-439

Kramer, W., Oliva, A., Stryi-Hipp, G., Kobelt, S., Bestenlehner, D., Drück, H., Bühl, J., Dasch, G. (2013) Solar-active-houses - analysis of the building concept based on detailed measurements. Proceedings of the International Conference on Solar Heating and Cooling for Buildings and Industry, September 23-15, 2013, Freiburg, Germany

Nuñez, T., Malenković, I., Mugnier, D., Döll, J., Schossig, P. (2011) Proposal for a performance evaluation procedure for solar cooling applications. Proceedings of the $4^{\text {th }}$ International Conference on Solar Air-Conditioning, 12-14 October 2011, Larnaka, Cyprus

Papillon, P., Albaric, M., Haller, M., Haberl, R., Persson, T., Pettersson, U., Frank, E., Bales, C. (2011). Whole system testing: the efficient way to test and improve solar combisystems performance and quality. In: ESTEC 2011 - 5th European Solar Thermal Energy Conference, 20-21 October, Marseille, France

Perers, B., Kovacs P., Pettersson U., Björkman J. (2011) Validation of a Dynamic Model for Unglazed Collectors Including Condensation. Application for Standardised Testing and Simulation in TRNSYS and IDA. ISES Solar World Congress, Kassel, Germany 
United Nations (2011), International Recommendations for Energy Statistics (IRES), draft version. United nations, New York, USA. Available from http://unstats.un.org/unsd/statcom /doc11/BG-IRES.pdf

VDI (2004) VDI 6002, Blatt 1: Solare Trinkwassererwärmung - Allgemeine Grundlagen, Systemtechnik und Anwendung im Wohnungsbau. VDI, Düsseldorf, Germany

Wemhöner, C., Afjei, T. (2003) Seasonal performance calculation for residential heat pumps with combined space heating and hot water production (FHBB Method). Final project report within the research program Heat Pump Technologies, Cogeneration, Refrigeration of the Swiss Federal Office of Energy. University of Applied Sciences Basel, Institute of Energy, Muttenz, Switzerland 


\section{Annex 1: Reviewed standards and other normative documents}

[1] CEN (2011) EN 14511:2011 Air conditioners, liquid chilling packages and heat pumps with electrically driven compressors for space heating and cooling. CEN, Brussels, Belgium

[2] CEN (2011) EN 15879-1:2011 Testing and rating of direct exchange ground coupled heat pumps with electrically driven compressors for space heating and/or cooling. Direct exchange-to-water heat pumps. CEN, Brussels, Belgium

[3] CEN (2011) EN 16147:2011 Heat pumps with electrically driven compressors - Testing and requirements for marking for domestic hot water units. CEN, Brussels, Belgium

[4] AHRI (1998) AHRI Standard 320-98 Water-Source Heat Pumps. AHRI, Arlington, USA

[5] AHR (1998) AHRI Standard 325-98 Ground Water-Source Heat Pumps. AHRI, Arlington, USA

[6] AHRI (1998) AHRI Standard 330-98 Ground Source Closed-Loop Heat Pumps. AHRI, Arlington; USA

[7] ISO (1998) ISO 13256-1:1998 Water-source heat pumps - Testing and rating for performance, Part 1: Water-to-air and brine-to-air heat pumps. International Organization for Standardisation, Geneva, Switzerland

[8] ISO (1998) ISO 13256-2:1998 Water-source heat pumps - Testing and rating for performance, Part 1: Water-to-water and brine-to-water heat pumps. International Organization for Standardisation, Geneva, Switzerland

[9] CEN (2011) EN14825:2011 Air conditioners, liquid chilling packages and heatpumps, with electrically driven compressors, for space heating and cooling - Testing and rating at part load conditions and calculation of seasonal performance, CEN, Brussels, Belgium

[10] ASHRAE (2010) ASHRAE 116 - 2010 Methods of Testing for Rating Seasonal Efficiency of Unitary Air Conditioners and Heat Pumps. ASHRAE, Atlanta, USA

[11] VDI (2003) VDI 4650-1: Calculation of heat pumps - Simplified method for the calculation of the seasonal performance factor of heat pumps - Electric heat pumps for space heating and domestic hot water. VDI, Düsseldorf, Germany

[12] CEN (2008) EN15316-4-2:2008 Heating systems in buildings - Method for calculation of system energy requirements and system efficiencies - Part 4-2: Space heating generation systems, heat pump systems. CEN, Brussels, Belgium

[13] CEN (2006) EN 12975-1:2006 Thermal solar systems and components. Solar collectors. Test methods. CEN, Brussels, Belgium 
[14] ISO (1995) ISO 9806-3 Test methods for solar collectors -- Part 3: Thermal performance of unglazed liquid heating collectors (sensible heat transfer only) including pressure drop. International Organization for Standardisation, Geneva, Switzerland

[15] ASHRAE (2010) ASHRAE 93-2010 Methods of Testing to Determine the Thermal Performance of Solar Collectors. ASHRAE, Atlanta, USA

[16] CEN (2012) EN 12976-2:2012 Thermal solar systems and components - Factory made systems - Part 2: Test methods. CEN, Brussels, Belgium

[17] CEN (2011-2012) EN 12977 Thermal solar systems and components. Custom built systems, Parts 1-5. CEN, Brussels, Belgium

[18] ISO (1993-2013) ISO 9459 Soalar heating - Domestic water heating systems, Parts 1, 2, 4 and 5. International Organization for Standardisation, Geneva, Switzerland

[19] CEN (2007) EN 16316-4-3 Heating systems in buildings. Method for calculation of system energy requirements and system efficiencies. Heat generation systems, thermal solar systems. CEN, Brussels, Belgium

[20] ISO (1999) ISO 9488:1999 - Solar energy - Vocabulary. International Organization for Standardisation, Geneva, Switzerland 